\title{
Intrinsic Plasticity Complements Long-Term Potentiation in Parallel Fiber Input Gain Control in Cerebellar Purkinje Cells
}

\author{
Amor Belmeguenai, ${ }^{1,2,3 \star}$ Eric Hosy, ${ }^{1 \star}$ Fredrik Bengtsson, ${ }^{4^{\ddagger}}$ Christine M. Pedroarena, ${ }^{5}{ }^{\ddagger}$ Claire Piochon, ${ }^{6}$ Eva Teuling, ${ }^{1,6}$ \\ Qionger He, ${ }^{6}$ Gen Ohtsuki, ${ }^{1,6}$ Marcel T. G. De Jeu, ${ }^{1}$ Ype Elgersma, ${ }^{1}$ Chris I. De Zeeuw, ${ }^{1,7}$ Henrik Jörntell, ${ }^{4}$ \\ and Christian Hansel ${ }^{1,6}$ \\ ${ }^{1}$ Department of Neuroscience, Erasmus University Medical Center, 3000CA Rotterdam, The Netherlands, ${ }^{2}$ Université de Lyon, Université Lyon 1, Centre \\ National de la Recherche Scientifique, Unité Mixte de Recherche 5123, Villeurbanne, France, ${ }^{3}$ CTRS-IDEE, Hospices Civils de Lyon, Lyon, France, \\ ${ }^{4}$ Department of Experimental Medical Science, Section for Neuroscience, Lund University, 22184 Lund, Sweden, ${ }^{5}$ Department of Cognitive Neurology, \\ Hertie-Institute for Clinical Brain Research, University of Tübingen, 72076 Tübingen, Germany, ${ }^{6}$ Department of Neurobiology, University of Chicago, \\ Chicago, Illinois 60637, and 7Netherlands Institute for Neuroscience, Royal Academy of Sciences (KNAW), 1105 BA Amsterdam, The Netherlands
}

Synaptic gain control and information storage in neural networks are mediated by alterations in synaptic transmission, such as in long-term potentiation (LTP). Here, we show using both in vitro and in vivo recordings from the rat cerebellum that tetanization protocols for the induction of LTP at parallel fiber (PF)-to-Purkinje cell synapses can also evoke increases in intrinsic excitability. This form of intrinsic plasticity shares with LTP a requirement for the activation of protein phosphatases $1,2 \mathrm{~A}$, and $2 \mathrm{~B}$ for induction. Purkinje cell intrinsic plasticity resembles CA1 hippocampal pyramidal cell intrinsic plasticity in that it requires activity of protein kinase A (PKA) and casein kinase 2 (CK2) and is mediated by a downregulation of SK-type calcium-sensitive K conductances. In addition, Purkinje cell intrinsic plasticity similarly results in enhanced spine calcium signaling. However, there are fundamental differences: first, while in the hippocampus increases in excitability result in a higher probability for LTP induction, intrinsic plasticity in Purkinje cells lowers the probability for subsequent LTP induction. Second, intrinsic plasticity raises the spontaneous spike frequency of Purkinje cells. The latter effect does not impair tonic spike firing in the target neurons of inhibitory Purkinje cell projections in the deep cerebellar nuclei, but lowers the Purkinje cell signal-to-noise ratio, thus reducing the PF readout. These observations suggest that intrinsic plasticity accompanies LTP of active PF synapses, while it reduces at weaker, nonpotentiated synapses the probability for subsequent potentiation and lowers the impact on the Purkinje cell output.

\section{Introduction}

A classic view in neuroscience holds that information storage and learning in neural circuits are made possible by alterations in synaptic transmission such as long-term potentiation (LTP) and long-term depression (LTD). In the cerebellum, for example, bidirectional plasticity at PF-to-Purkinje cell synapses may be involved in motor learning (Ito, 1984; Jörntell and Hansel, 2006). More recently, plasticity of the intrinsic excitability of neurons has received attention as a potential correlate of learning (Hansel et al., 2001; Zhang and Linden, 2003; Frick and Johnston, 2005; Mozzachiodi and Byrne, 2010), but it remains unclear how intrinsic plasticity complements synaptic plasticity in memory for-

\footnotetext{
Received June 22, 2010; revised Aug. 6, 2010; accepted Aug. 9, 2010.

This study was supported by grants from De Nederlandse Organisatie voor Wetenschappelijk Onderzoek (separate grants to A.B., C.I.D.Z., and C.H.), SENSOPAC and the Prinses Beatrix Fonds (C.I.D.Z.), SF (C.P.), the Swedish Medical Research Council (H.J.), and National Institute of Neurological Disorders and Stroke Grant NS-62771 (C.H.). We thank M. Brecht, C.-F. Ekerot, and members of the participating laboratories for comments, and S. Tonegawa for providing the CNB1 mice. We thank J. Adelman for providing SK2 ${ }^{-1-}$ mice.

*A.B. and E.H. contributed equally to this work (co-first authors).

${ }^{\ddagger} F . B$. and C.M.P. contributed equally to this work (co-second authors).

Correspondence should be addressed to Christian Hansel, University of Chicago, Department of Neurobiology, 947 East 58th Street, Chicago, IL 60637. E-mail: chansel@bsd.uchicago.edu.

E. Hosy's present address: Bordeaux Neuroscience Institute, University of Bordeaux, France.

E. Teuling's present address, Department of Genetics, University of Groningen, The Netherlands.

DOI:10.1523/JNEUROSCI.3226-10.2010

Copyright $\odot 2010$ the authors $\quad$ 0270-6474/10/3013630-14\$15.00/0
}

mation. Excitability changes result from modifications of voltage- or calcium-dependent ion channels. So far, different types of $\mathrm{K}$ channels have been implicated in intrinsic plasticity, including A-type K channels (Schreurs et al., 1998; Frick et al., 2004), calcium-activated BK channels (Nelson et al., 2005), and SK channels (Sourdet et al., 2003; Lin et al., 2008). Moreover, it has been shown that activity-dependent alterations in hyperpolarization-activated $I_{\mathrm{h}}$ currents can adjust the excitability of neurons (Wang et al., 2003; Fan et al., 2005; Brager and Johnston, 2007).

In cerebellar circuits, activity-dependent intrinsic plasticity has been described in granule cells (Armano et al., 2000), Purkinje cells (Schreurs et al., 1998), as well as in the target neurons of Purkinje cells in the deep cerebellar nuclei (DCN) (Aizenman and Linden, 2000) and the vestibular nuclei (Nelson et al., 2005). In Purkinje cells, BK channel downregulation results in cerebellar ataxia (Sausbier et al., 2004), while an enhancement of SK channel function has been shown to improve ataxia (Walter et al., 2006). These observations show how crucial the control of Purkinje cell activity patterns and intrinsic excitability is for proper motor coordination and suggest that Purkinje cells might use activity-dependent excitability alterations to fine-adjust the electrical output of the cerebellar cortex.

During recent years, research on the cellular basis of cerebellar motor learning has largely focused on LTD at PF synapses onto 

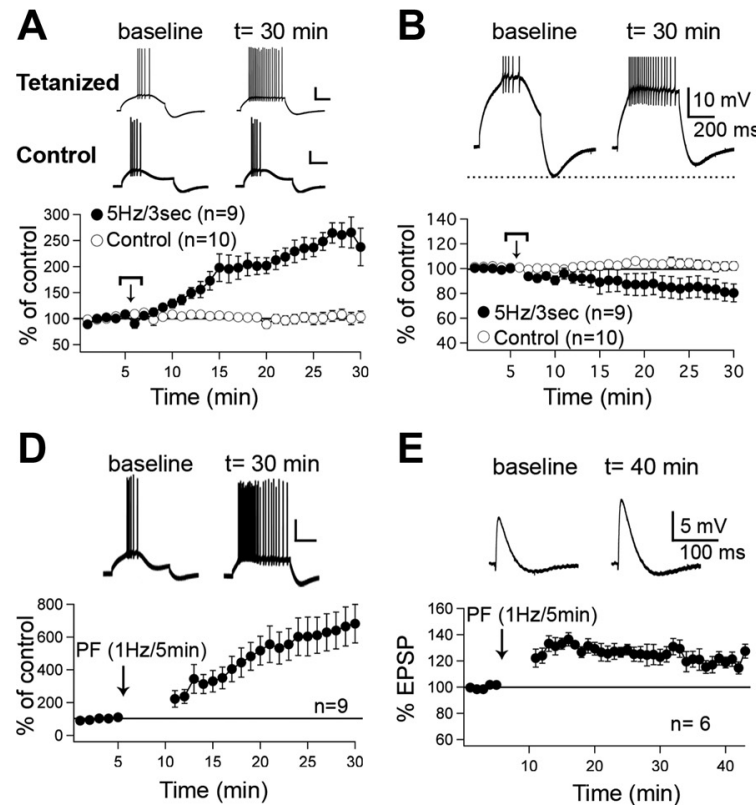

E
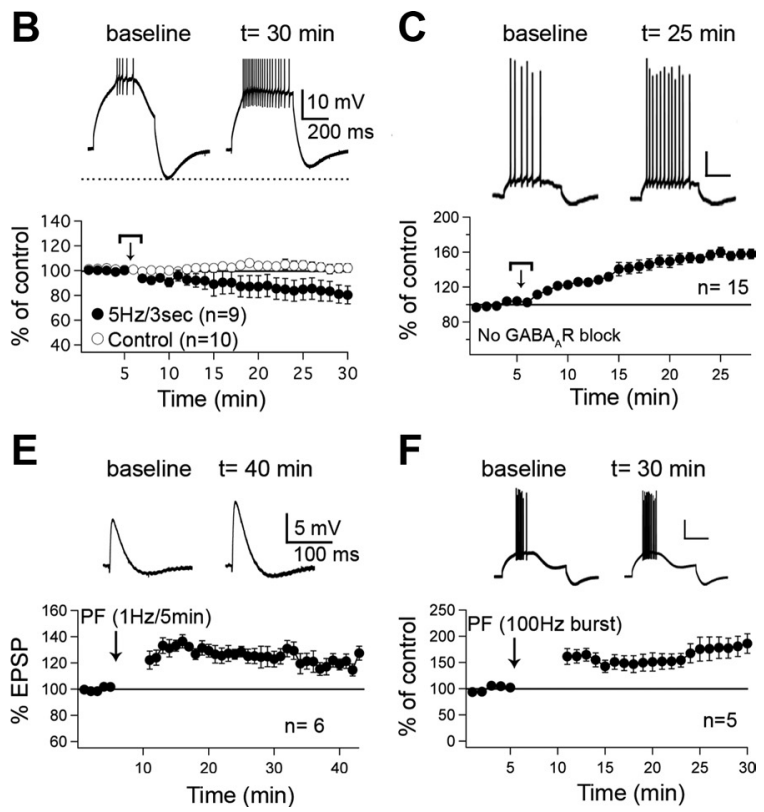

Figure 1. Purkinje cell intrinsic plasticity can be elicited by application of repeated current steps or by PF tetanization. $\boldsymbol{A}$, Repeated injection of depolarizing currents ( $5 \mathrm{~Hz}, 3 \mathrm{~s} /$ pulse duration: $100 \mathrm{~ms}$; amplitude: $50-100 \mathrm{pA}$ higher than in test pulses) enhanced the spike count $(n=9)$. Under control conditions, the spike count remained stable $(n=10)$. In these and the following in vitro experiments shown in this figure, spontaneous spike activity was prevented by the injection of hyperpolarizing bias currents. Calibration: $20 \mathrm{mV}, 200 \mathrm{~ms}$, unless stated otherwise. $\boldsymbol{B}$, Following tetanization, the AHP amplitude was reduced $(n=9)$, but remained stable under control conditions $(n=10)$. The traces shown on top are identical to those shown in the top row in $A$, but are displayed using different scaling to allow for a better view of the AHP transients. C, Intrinsic plasticity was also observed in the absence of GABA receptor blockers in the bath $(n=15)$. $\boldsymbol{D}$, PF stimulation ( $1 \mathrm{~Hz}, 5 \mathrm{~min})$ enhanced the spike count $(n=9) . \boldsymbol{E}$, The same PF stimulation protocol elicited LTP of PF-EPSPs $(n=6) . F, 100 \mathrm{~Hz}$ PF burst stimulation triggered an increase in intrinsic excitability $(n=5)$. Arrows indicate the time point of tetanization. Application of the nonsynaptic depolarization protocol is indicated by the current step symbol. In all recordings except for the experiments shown in $C, G A B A_{A}$ receptors were blocked. Error bars indicate SEM.

Purkinje cells, and more recently on LTP (Lev-Ram et al., 2002; Jörntell and Hansel, 2006; Dean et al., 2010). It has to be kept in mind, however, that the total synaptic gain (the gain of neuronal responsiveness to synaptic activity) can be modified, not only by changing properties of synaptic transmission (as in LTD and LTP), but also by local modifications of intrinsic excitability. To examine whether Purkinje cell intrinsic plasticity can play a role in cerebellar information storage, we characterized the cellular mechanisms underlying intrinsic excitability alterations, and determined how intrinsic plasticity affects the spontaneous activity of Purkinje cells and PF synaptic gain.

\section{Materials and Methods}

Purkinje cell recordings in vitro. Sagittal slices of the cerebellar vermis (250 $\mu \mathrm{m})$ were prepared from postnatal day 17 (P17)-P28 Sprague Dawley rats after decapitation and isoflurane anesthesia. This procedure is in accordance with the guidelines of the Animal Care and Use Committees of both the Erasmus University Medical Center and the University of Chicago. In some experiments, mice (P17-P28) were used, as specified below. The slices were cut on a vibratome (Leica VT1000S) using ceramic blades. Subsequently, the slices were kept in artificial CSF (ACSF) containing the following (in mM): $124 \mathrm{NaCl}, 5 \mathrm{KCl}, 1.25 \mathrm{Na}_{2} \mathrm{HPO}_{4}, 2 \mathrm{MgSO}_{4}$, $2 \mathrm{CaCl}_{2}, 26 \mathrm{NaHCO}_{3}$, and 10 D-glucose, bubbled with $95 \% \mathrm{O}_{2}$ and $5 \%$ $\mathrm{CO}_{2}$. The slices were allowed to recover for at least $1 \mathrm{~h}$, and were then transferred to a submerged recording chamber superfused with ACSF at near-physiological temperature $\left(34-35^{\circ} \mathrm{C}\right)$. In some recordings, the ACSF was supplemented with either $20 \mu \mathrm{m}$ bicuculline methiodide or $100 \mu \mathrm{M}$ picrotoxin to block $\mathrm{GABA}_{\mathrm{A}}$ receptors. Picrotoxin was used in some experiments, as bicuculline salts have been reported to interfere with SK channel function (Seutin and Johnson, 1999). In our hands, however, intrinsic plasticity was observed independent of the type of antagonist used (bicuculline: Fig. $1 A, B, D, E$; picrotoxin: Fig. $1 F)$. Whole-cell patch-clamp recordings were performed under visual control using a $40 \times$ water-immersion objective mounted on a Zeiss Axioskop 2FS microscope. Patch pipettes (3-4 $\mathrm{M} \Omega$ ) were filled with internal saline containing the following (in $\mathrm{mm}$ ): $9 \mathrm{KCl}, 10 \mathrm{KOH}, 120$ K-gluconate, $3.48 \mathrm{MgCl}_{2}$, 10 HEPES, $4 \mathrm{NaCl}, 4$ $\mathrm{Na}_{2} \mathrm{ATP}, 0.4 \mathrm{Na}_{3} \mathrm{GTP}$, and 17.5 sucrose, $\mathrm{pH}$ adjusted to 7.25. For cell-attached recordings, the pipette saline contained the following (in mM): $125 \mathrm{NaCl}, 10 \mathrm{HEPES}, 3 \mathrm{KCl}$, and $2 \mathrm{CaCl}_{2}$. All drugs were purchased from Sigma. Patchclamp recordings were performed in currentclamp mode (capacitance cancellation switched off) using an EPC-10 amplifier (HEKA Electronics). Membrane voltage and current were filtered at $3 \mathrm{kHz}$, digitized at 8 $\mathrm{kHz}$ (for action potential kinetics: $33 \mathrm{kHz}$ ), and acquired using Pulse software (HEKA Electronics). In the majority of recordings, a hyperpolarizing bias current was applied to prevent spontaneous spike activity. In some experiments (see Fig. 8), injection of bias currents was used to adjust the background spike rate of Purkinje cells. For PF stimulation, glass pipettes filled with ACSF were placed in the molecular layer, and for CF stimulation in the granule cell layer. Test responses were evoked at a frequency of $0.05 \mathrm{~Hz}$ using $\sim 3 \mu \mathrm{A}$ pulses that were applied for $500 \mu$ s. Intrinsic plasticity was monitored during the test periods by injection of brief (550 ms) depolarizing current pulses (100-200 pA) adjusted to evoke 5-15 spikes. The spike count was taken as a measure of excitability. Input resistance $\left(R_{\mathrm{i}}\right)$ was measured by injection of hyperpolarizing test currents $(200 \mathrm{pA} ; 100 \mathrm{~ms})$ and was calculated from the voltage transient toward the end of current injection.

Confocal calcium imaging. Calcium transients were recorded using a Zeiss LSM 5 Exciter confocal microscope equipped with a $\times 63$ Zeiss Apochromat objective (Carl Zeiss MicroImaging). Fluorescence was excited at $488 \mathrm{~nm}$ using an argon laser (Lasos Lasertechnik). For the calcium imaging experiments, sagittal slices of the cerebellar vermis (190-220 $\mu \mathrm{m})$ were prepared from postnatal day 23-31 Sprague Dawley rats. Purkinje cells were loaded with the fluorescent calcium indicator dye Oregon Green BAPTA-2 $(200 \mu \mathrm{M})$. After 10 min of dye loading, the patch pipette was removed and the dye was allowed to diffuse into the dendrite for another $\sim 40 \mathrm{~min}$. Subsequently, the cell was repatched with a second dye-filled patch electrode. This repatching protocol was used to avoid wash-out effects that might result from too long exposure to the pipette saline. The ACSF was supplemented with picrotoxin $(100 \mu \mathrm{M})$, and in some experiments with the anti-oxidant vitamin C $(100 \mu \mathrm{M})$. The recordings were performed at room temperature. Intrinsic plasticity was monitored using current pulses as in the nonimaging experiments, before and after tetanic current injection. Spine calcium transients were triggered by $100 \mathrm{~Hz}$ PF stimulation at intervals of $0.5-2 \mathrm{~min}$. The number of PF pulses was adjusted to evoke a pronounced calcium transient (2-8 pulses). Before tetanization, calcium transients were recorded during a $10 \mathrm{~min}$ baseline period. For each sweep, the data acquisition frequency was in the range of $19-58 \mathrm{~Hz}$, depending on the size of the selected region of interest. Fluorescence changes were normalized to resting levels and expressed as the ratio $\Delta F / F(t)=[F(t)-F] / F$, where $F(t)$ is the fluorescence value at time $t$, and $F$ is the averaged fluorescence obtained during the baseline period preceding the stimulus application. Data were discarded when changes in the baseline fluorescence exceeded $20 \%$, with the 
exception of recordings (then up to $25 \%$ ) in which the change in the spine calcium transient (area) was at least twice as large.

Genetically modified mice. Mutant mice with a Purkinje cell-specific deletion of calcineurin (PP2B) were obtained by crossing the floxed CNB1 line (Zeng et al., 2001) with a L7-Cre line (Barski et al., 2000), resulting in a Purkinje cell-specific knock-out of the regulatory subunit (CNB1) of PP2B (C57BL6/OlaHsd background). Littermates of the following genotypes were used for the experiments: PP2B-lox/PP2B-lox/ L7Cre (L7-PP2B) and PP2B-lox/PP2B-lox (littermate controls). $\alpha$ CaMKII knock-out mice (Elgersma et al., 2002) and littermate control mice were obtained by breeding heterozygous knock-out mice in the C57BL6/OlaHsd background.

Purkinje cell recordings in vivo. To obtain single unit recordings in a nonanesthetized in vivo preparation, adult Sprague Dawley rats were decerebrated as previously described (Bengtsson and Jörntell, 2007). After decerebration, the rats were paralyzed and mounted in a stereotaxic frame for increased mechanical stability. Tungsten-in-glass microelectrodes were used for unitary, extracellular Purkinje cell recordings (5-25 $\mu \mathrm{m}$ exposed tip). Tungsten-in-glass microelectrodes $(50-100 \mu \mathrm{m}$ exposed tip) for parallel fiber stimulation (intensity $10-30 \mu \mathrm{A}$, pulse width $0.1 \mathrm{~ms})$ were placed at middle depth of the molecular layer $(100-150 \mu \mathrm{m}$ depth from the surface), at 200-600 $\mu \mathrm{m}$ away from the recording electrode. Single-pulse PF stimulation was used to verify that simple spike activity was evoked in the recorded PC. Burst PF stimulation (15 pulses at $100 \mathrm{~Hz}$, repeated at $1 \mathrm{~Hz}$ for $5 \mathrm{~min}$ ) was delivered at intensities just above threshold for evoking simple spikes. The experimental procedures for the in vivo recordings were approved by the local Swedish Animal Research Ethics Committee.

DCN recordings in vitro. Cerebellar slices $(275-290 \mu \mathrm{m})$ from P16P20 rats were prepared and superfused with artificial CSF containing the following (in mM): $125 \mathrm{NaCl}, 2.5 \mathrm{KCl}, 1.3 \mathrm{NaH}_{2} \mathrm{PO}_{4}, 1.5 \mathrm{MgCl}, 26$ $\mathrm{NaHCO}_{3}, 20$ glucose, $2.5 \mathrm{CaCl}_{2}$. The solution was bubbled with $95 \% \mathrm{O}_{2}$ and $5 \% \mathrm{CO}_{2}$. Whole-cell recordings in current-clamp mode were obtained at $31^{\circ} \mathrm{C} \pm 0.5$ from large DCN neurons in the lateral or interpositus nuclei using an Axoclamp2B-amplifier (Molecular Devices). The intracellular electrode solution contained the following (in $\mathrm{mM}$ ): 134 K-gluconate, $6 \mathrm{KCl}$, $10 \mathrm{~K}$-HEPES, 0.1 EGTA, 0.3 NaGTP, 2 K-ATP, 10 phosphocreatine, $2 \mathrm{MgCl}_{2}$. All recorded DCN neurons showed spontaneous firing $(7.9-38 \mathrm{~Hz})$ and triphasic afterhyperpolarizations (AHPs). Here, we took advantage of an in vitro preparation to investigate the effect of enhanced tonic Purkinje cell spike firing on spontaneous spike firing in DCN neurons. It has been pointed out that DCN spike patterns in vivo might be different than in slices (Alviña et al., 2008). However, the tonic spike frequency ranges reported here are well within the ranges found in awake rat DCN recordings (LeDoux et al., 1998); thus, it is unlikely that tonic Purkinje cell firing affects spontaneous firing in DCN neurons differently in vivo. Purkinje cell axons were stimulated using a pair of tungsten microelectrodes located in the white matter around the cerebellar nuclei. The stimulus intensity was adjusted at $0.1 \mathrm{~Hz}$ to induce a pause in the spontaneous firing of DCN neurons. Kynurenic acid ( $3 \mathrm{~mm}$ ) was bath applied to block excitatory neurotransmission. Repetitive stimulation was applied at 33.3 and $50 \mathrm{~Hz}$. The switch from 33.3 to $50 \mathrm{~Hz}$ was applied after $2-4 \mathrm{~min}$ of stimulation at $33.3 \mathrm{~Hz}$. Recordings were digitized and stored using programmable software (Spike 2, Cambridge Electronic Design). These procedures were done according to guidelines of the University of Tübingen and the local Committee on Animal Care and Use.

Immunohistochemistry. Two-week-old, four-week-old, and adult (3-4 months old) rats were anesthetized with pentobarbital and perfused transcardially with $4 \%$ paraformaldehyde. The brain was carefully dissected, postfixed in $4 \%$ paraformaldehyde for $1 \mathrm{~h}$ at $4^{\circ} \mathrm{C}$, and rinsed overnight in $0.1 \mathrm{M}$ phosphate buffer $(\mathrm{PB})$ containing $30 \%$ sucrose. Forty micrometer sections of the cerebellum were cut on a freezing microtome and collected in $0.1 \mathrm{M}$ PB. Sections were heated up in $0.25 \mathrm{~m}$ sodium citrate to $80^{\circ} \mathrm{C}$ for $30 \mathrm{~min}$, rinsed in TBS, and blocked in TBS containing $10 \%$ normal horse serum (NHS) and $0.5 \%$ Triton, for $1 \mathrm{~h}$ at room temperature. Sections were incubated for $48-72 \mathrm{~h}$ at $4^{\circ} \mathrm{C}$ in TBS containing $2 \%$ NHS, $0.4 \%$ Triton, and primary antibodies at the following concentrations: rabbit anti-SK2 (Alomone or Sigma) 1:500; mouse-anti calbi- ndin (Sigma) 1:1000. Subsequently, sections were rinsed in TBS, incubated with FITC- or Cy3- (Jackson ImmunoResearch) conjugated goat-anti-mouse or goat-anti-rabbit secondary antibodies at 1:200 for $1.5-2 \mathrm{~h}$ at room temperature. Sections were rinsed again in TBS and mounted directly on coverslips. Fluorescence images were taken with a Zeiss LSM 510 confocal laser-scanning microscope. The rabbit anti-SK2 channel antibodies obtained from both Alomone and Sigma were directed against a sequence in the $\mathrm{C}$-terminal domain of SK2 channel subunits, which corresponds to amino acids 542-559. The immunostainings obtained with both antibodies were very similar, which is why we only show stainings obtained with the anti-SK2 antibody purchased from Alomone Labs (see Fig. 4). The specificity of this antibody was confirmed using slices from SK2 ${ }^{-1-}$ mice and littermate controls (supplemental Fig. 6, available at www.jneurosci.org as supplemental material) (for protocol details, see Piochon et al., 2007).

Data analysis. Data obtained from the Purkinje cell recordings in vitro were analyzed using Pulsefit (HEKA Electronics) and Igor Pro software (WaveMetrics). For statistical analysis, we used the paired Student's $t$ test and the Mann-Whitney $U$ test, when appropriate. Peristimulus time histograms (PSTHs) and cumulative spike probabilities (see Fig. 8) were calculated using SigmaPlot software (Hearne Scientific Software). Data obtained from the in vivo recordings were analyzed using the two-tailed Student's $t$ test. Data obtained from the DCN neuron recordings were analyzed off-line using programmable software Spike 2 (Cambridge Electronic Design), Igor (WaveMetrics), and SigmaStat (SPSS). Statistical analysis was performed using the Wilcoxon signed-rank test on data taken from $100 \mathrm{~s}$ before and $100 \mathrm{~s}$ after the switch from 30 to 50 $\mathrm{Hz}$ stimulation. The data from the first $10 \mathrm{~s}$ after the switch were excluded from the analysis. In all figures, the values shown represent the mean \pm SEM.

\section{Results}

\section{Purkinje cell intrinsic plasticity can be observed in vitro and in vivo}

To monitor intrinsic excitability changes in Purkinje cells, we performed whole-cell patch-clamp recordings in cerebellar slices (250 $\mu \mathrm{m}$ thick) obtained from P17-P28 Sprague Dawley rats at near-physiological temperature $\left(34-35^{\circ} \mathrm{C}\right)$. Intrinsic excitability was measured in current-clamp mode by injecting brief depolarizing currents $(\sim 100-200 \mathrm{pA})$ that at the beginning of the recordings were adjusted to evoke 5-15 spikes. During the test periods before and after tetanization, these current steps were delivered at $0.05 \mathrm{~Hz}$. GABA receptors were blocked by bath application of bicuculline methiodide $(20 \mu \mathrm{M})$ or picrotoxin $(100$ $\mu \mathrm{M})$. In these recordings, the number of depolarization-evoked spikes was taken as a measure of Purkinje cell excitability. An enhanced spike count was observed after repeated injection of depolarizing currents that were delivered at $5 \mathrm{~Hz}$ for $3 \mathrm{~s}$ (255.4 \pm $20.3 \%$ of baseline \pm SEM; $n=9$; last $5 \mathrm{~min} ; p=0.00006$ ) (Fig. $1 A)$. Under control conditions, the spike count remained stable $(103.4 \pm 10.9 \% ; n=10 ; p=0.19)$ (Fig. $1 A)$. In the same recordings, we also monitored the amplitude of the AHP following the depolarizing current steps. After tetanization, the AHP amplitude was significantly reduced $(81.9 \pm 7.2 \% ; n=9 ; p=0.02985)$ (Fig. $1 B$ ), but remained stable under control conditions (102.2 \pm $3.3 \% ; n=10 ; p=0.47$ ) (Fig. $1 B$ ). Intrinsic plasticity was also observed when no $\mathrm{GABA}_{\mathrm{A}}$ receptor antagonists were present in the bath (spike count: $155.2 \pm 5.4 \% ; n=15 ; p=0.000007$ ) (Fig. $1 C)$. However, the excitability increase was significantly larger when inhibition was blocked $(p=0.00006)$, suggesting that spontaneous GABAergic transmission limits intrinsic plasticity.

A pronounced increase in the number of depolarizationevoked spikes was also observed following PF tetanization $(1 \mathrm{~Hz}$, 5 min: $645.0 \pm 113.9 \% ; n=9 ; p=0.00138$ ) (Fig. $1 D)$. This $1 \mathrm{~Hz}$ PF stimulation protocol has previously been used for PF-LTP induction (Coesmans et al., 2004), and reliably elicited LTP un- 
der the recording conditions described here $(120.8 \pm 5.0 \% ; n=$ $6 ; p=0.00198)($ Fig. $1 E$ ). Finally, we adopted a PF burst protocol (10-15 pulses at $100 \mathrm{~Hz}$, repeated at $1-3 \mathrm{~s}$ intervals for $5 \mathrm{~min}$ ), which was designed to reflect granule cell activity patterns in vivo (Chadderton et al., 2004; Jörntell and Ekerot, 2006). Application of this $100 \mathrm{~Hz}$ PF burst protocol triggered intrinsic plasticity $(179.6 \pm 19.8 \% ; n=5 ; p=0.00388)$ (Fig. $1 F)$, and elicited LTP (supplemental Fig. 1, available at www.jneurosci.org as supplemental material) (see also Smith and Otis, 2005). None of these three tetanization protocols caused a significant change in the input resistance (current injection protocol: $100.3 \pm 2.5 \% ; n=9$; $p=0.91 ; 1 \mathrm{~Hz}$ PF protocol: $96.8 \pm 4.7 \% ; n=9 ; p=0.08 ; 100 \mathrm{~Hz}$ PF protocol: $100.0 \pm 0.5 \% ; n=5 ; p=0.95$ ) (supplemental Table 1 , available at www.jneurosci.org as supplemental material). However, intrinsic plasticity (current step protocol) (Fig. 1A) was associated with a decrease in the spike threshold (required current injection from $-65 \mathrm{mV}$; before: $260.7 \pm 54.2 \mathrm{pA}$; after tetanization: $225.0 \pm 46.9 \mathrm{pA} ; n=7 ; p=0.0465$ ).

To evaluate the physiological relevance of Purkinje cell intrinsic plasticity, we performed unitary, extracellular Purkinje cell recordings in nonanesthetized, decerebrated adult rats (P60P90). In these in vivo recordings, the spontaneous spike rate was $42.4 \pm 4.9 \mathrm{~Hz}$ (control recordings; $n=5$ ). Application of the 100 $\mathrm{Hz} \mathrm{PF}$ burst protocol caused an increase in the rate of spontaneous spike firing of Purkinje cells (control: $100.1 \pm 1.0 \% ; n=5$; $p=0.34$; after tetanization: $115.0 \pm 2.8 \% ; n=5 ; p=0.0023$ ) (Fig. $2 A, B$ ). Application of the $1 \mathrm{~Hz}$ PF stimulation protocol did not result in spike rate changes (supplemental Fig. 2, available at www.jneurosci.org as supplemental material). These in vivo recordings differ from the intrinsic plasticity experiments shown in Figure 1, in that the spontaneous spike rate (rather than the number of depolarization-evoked spikes) was measured and inhibition was left intact, thus allowing us to assess intrinsic plasticity under more physiological conditions. To examine whether intrinsic plasticity can be observed under these conditions in vitro, we applied both the current step protocol and the $100 \mathrm{~Hz}$ PF burst protocol, respectively, to cerebellar slices, when GABAergic inhibition was left intact, and Purkinje cells were allowed to spontaneously discharge (hyperpolarizing bias currents were omitted), resulting in an average background spike rate of $24.1 \pm 2.9 \mathrm{~Hz}$ (control recordings; $n=8$ ) (Fig. 2C). Under these conditions, repeated current injection induced a lasting increase in the spike rate $(140.9 \pm 15.3 \% ; n=10 ; p=0.02565$; control: $85.7 \pm 5.9 \%$; $n=8 ; p=0.04557$ ) (Fig. 2C). Application of the $100 \mathrm{~Hz}$ PF burst protocol also resulted in an increase in the background spike rate $(175.2 \pm 15.4 \% ; n=8 ; p=0.00024)$ (Fig. $2 D)$. As the in vivo recordings were performed using $\mathrm{P} 60-\mathrm{P} 90$ rats, we also examined whether intrinsic plasticity can be observed in that age group in vitro. In recordings from P60-P100 Purkinje cells in slices, we indeed observed an excitability increase when the $100 \mathrm{~Hz} \mathrm{PF}$ stimulation protocol was applied (spike count: $280.6 \pm 24.9 \%$, $n=8 ; p=0.00001$ ) (supplemental Fig. 3, available at www. jneurosci.org as supplemental material). These recordings suggest that intrinsic plasticity is a robust phenomenon that can be observed both in vitro and in vivo, in young adult and adult animals, and in the absence and presence of $\mathrm{GABA}_{\mathrm{A}}$ receptor blockers. Furthermore, the change in intrinsic excitability can be monitored when counting depolarization-evoked spikes, or when measuring spontaneous spike activity. It can be argued that both whole-cell patch-clamp recordings from Purkinje cells in vitro and single-unit recordings in vivo might disrupt physiological Purkinje cell responses. We thus additionally characterized intrinsic plasticity using cell-attached recordings in vitro, which

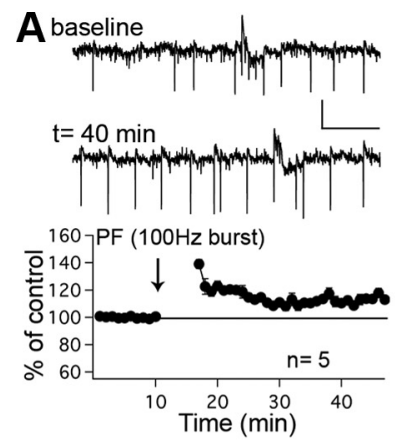

B

In vivo (extracellular)

\section{C}
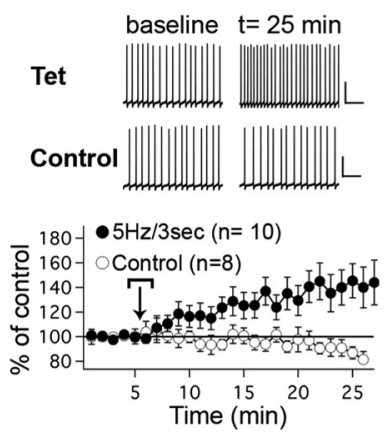

E

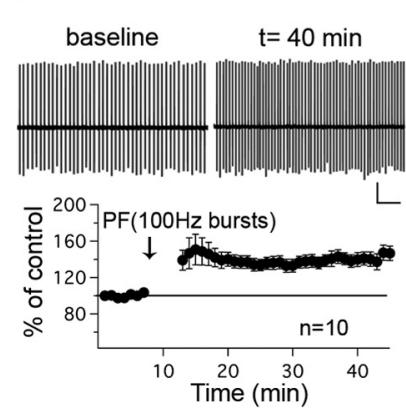

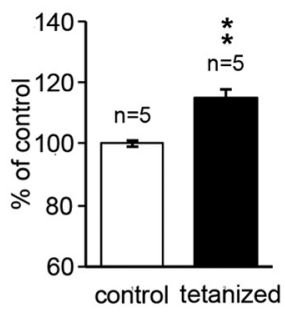

D In vitro (patch-clamp)
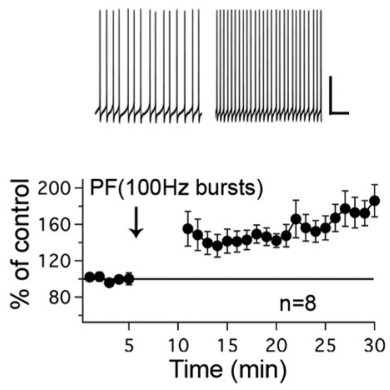

F In vitro (cell-attached)

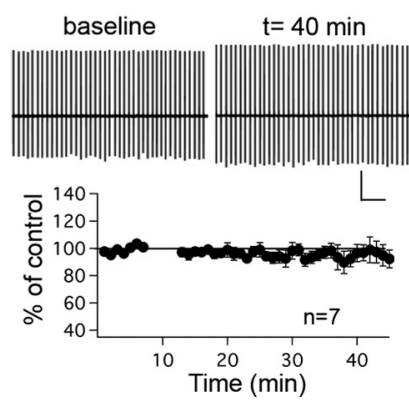

baseline $t=30 \mathrm{~min}$

Figure 2. Changes in the spontaneous Purkinje cell spike rate recorded in vivo and in vitro. $\boldsymbol{A}$, $100 \mathrm{~Hz}$ PF burst stimulation caused an increase in simple spike firing in vivo $(n=5)$. The time graph shows the percentage change of the recorded spike frequency $(\mathrm{Hz})$. The traces show single-unit extracellular recordings before (top) and after tetanization (bottom). Calibration: $0.2 \mathrm{mV}, 50 \mathrm{~ms}$. $\boldsymbol{B}$, Bar graph comparing the spike rate observed after PF burst stimulation ( $n=$ 5; 0-30 min after tetanus) to that measured under control conditions $(n=5)$. C, Repeated current injection enhanced the spontaneous Purkinje cell spike rate in vitro (closed circles; $n=$ 10). Under control conditions, the spike rate was not enhanced (open circles; $n=8$ ). $\boldsymbol{D}, 100 \mathrm{~Hz}$ PF tetanization also caused an increase in the tonic spike rate in vitro $(n=8) . C, D$, Calibration: $20 \mathrm{mV}, 200 \mathrm{~ms}$. $\boldsymbol{E}$, In cell-attached recordings in vitro, $100 \mathrm{~Hz}$ PF stimulation enhanced spontaneous spike firing $(n=10)$. $\boldsymbol{F}$, This increase was not seen under control conditions $(n=7)$. Calibration: $\boldsymbol{E}, 100 \mathrm{pA}, 200 \mathrm{~ms} ; \boldsymbol{F}, 200 \mathrm{pA}, 200 \mathrm{~ms}$. For these recordings, only cells were used that showed regular simple spike firing. The arrows indicate the time point of tetanization. All experiments shown in this figure were performed in the absence of $G_{A B A_{A}}$ receptor blockers in the bath. Error bars indicate SEM.

might provide a less invasive recording technique. When cellattached recordings were performed from P20-P27 rats, an average background spike frequency of $32.5 \pm 4.8 \mathrm{~Hz}$ (control recordings; $n=7$ ) (Fig. $2 F$ ) was observed. Application of the 100 $\mathrm{Hz} \mathrm{PF}$ burst protocol resulted in an increase in the spontaneous spike rate $(140.3 \pm 6.9 \% ; n=10 ; p=0.0002$; control: $94.9 \pm$ $6.6 \% ; n=7 ; p=0.83$ ) (Fig. $2 E, F)$. These cell-attached recordings confirm that intrinsic plasticity is a robust phenomenon that can be observed under a wide range of experimental conditions. In most subsequent experiments, we used the nonsynaptic cur- 
rent step protocol (Fig. 1A). GABAergic transmission was left intact, unless stated otherwise.

Intrinsic plasticity is mediated by a downregulation of SK channels

Intrinsic excitability changes can be mediated by alterations in voltage- or calciumsensitive ion channels (Zhang and Linden, 2003; Frick and Johnston, 2005). In adult Purkinje cells, high-quality dendritic voltage control is difficult to achieve. Because of this so-called "space-clamp" problem, we screened for types of ion channels involved by addressing three questions after bath application of ion channel antagonists: (1) Is the spike count upregulated after drug application? (2) Is there a change in the action potential waveform? and (3) Does application of an antagonist occlude an excitability increase caused by tetanic current injection $(5 \mathrm{~Hz}, 3 \mathrm{~s})$ ? Under control conditions, the amplitude and kinetics (rise time/spike width) of individual action potentials were unaffected after tetanization. Rather, we observed that after tetanization, the rate of depolarization toward spike threshold was enhanced following each action potential (Fig. $3 A, B$, Table 1) $(n=5)$, resulting in the elevated spike rate.

To determine the mechanism underlying this change in the firing rate, we first tested the effects of 4-aminopyridine (4AP), an antagonist of some types of voltagegated $\mathrm{Kv}$ channels, including A-type $\mathrm{K}$ currents $\left(I_{\mathrm{A}}\right)$. A previous study has demonstrated that delay eyeblink conditioning in rabbits is associated with an increase in Purkinje cell excitability (Schreurs et al., 1998), resembling similar excitability changes observed in CA1 pyramidal cells after trace eyeblink conditioning (Moyer et al., 1996). This type of Purkinje cell intrinsic plasticity was described as being mediated by changes in $I_{\mathrm{A}}$ (Schreurs et al., 1998). $I_{\mathrm{A}}$ has also been implicated in excitability alterations in CA1 hippocampal pyramidal cells in vitro (Ramakers and Storm, 2002; Frick et al., 2004). When 4-AP was bath applied $(100 \mu \mathrm{M})$, the spike count was significantly enhanced $(177.0 \pm 8.4 \%$; last 3 $\min ; n=11 ; p=0.000007$ ) (Fig. $3 C$ ). However, the width of individual action potentials was significantly increased, too (before: $0.27 \pm 0.03 \mathrm{~ms}$; 4 -AP: $0.44 \pm 0.04$ $\mathrm{ms} ; n=11 ; p=0.025)$ (Fig. 3C, Table 1). Such a prolongation was not seen under control conditions (before: $0.29 \pm 0.03$ $\mathrm{ms}$; after tetanization: $0.28 \pm 0.02 \mathrm{~ms} ; n=5 ; p=0.18$ ) (Table 1 ). Thus, a downregulation of 4-AP-sensitive Kv conductances does not mediate the form of intrinsic plasticity described here. Accordingly, bath application of 4-AP did not occlude further ex-
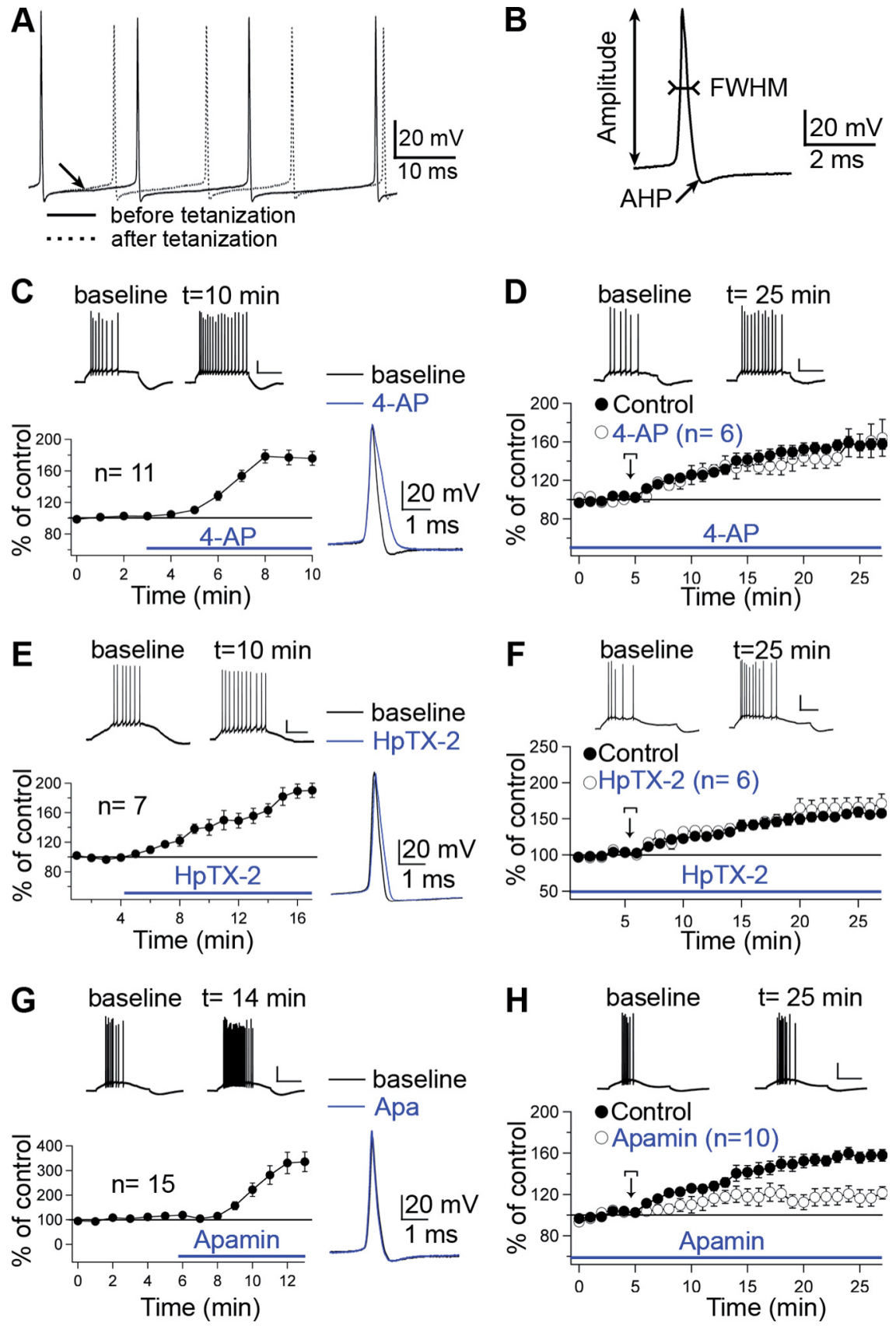

Figure 3. Cellular mechanisms underlying Purkinje cell intrinsic plasticity. A, Under control conditions, intrinsic plasticity was not associated with changes in the waveform of individual action potentials $(n=5)$. However, the spike rate was enhanced, because action potentials were followed by a faster depolarization toward spike threshold (arrow). $\boldsymbol{B}$, Parameters of the action potential waveform that were monitored, including the peak amplitude, the AHP amplitude, the $10-90 \%$ rise time, the full width at half magnitude (FWHM), and the rate of postspike depolarization (measured as the membrane potential, Em, $4.5-6 \mathrm{~ms}$ after the spike peak). C, Bath application of 4-AP (100 $\mu \mathrm{m})$ enhanced the spike count $(n=11)$, and prolonged the action potential width (right). D, 4-AP application did not block excitability increases triggered by tetanic current injection ( $n=6$ ). $\boldsymbol{E}$, Bath application of heteropodatoxin-2 (100 nM) also enhanced the spike count $(n=7)$ and slightly prolonged the spike width (right). $\boldsymbol{F}$, Heteropodatoxin-2 did not occlude excitability changes triggered by the current injection protocol $(n=6)$. $G$, Bath application of the SK-channel antagonist apamin $(3 \mathrm{~nm})$ increased the excitability $(n=15)$ without affecting the action potential waveform (right). $\boldsymbol{H}$, Apamin application partially occluded excitability increases following tetanic current injection $(n=10)$. In the occlusion experiments $(\boldsymbol{D}, \boldsymbol{F}, \boldsymbol{H})$, after drug application the spike count was readjusted to baseline levels by changing the current step/ holding current amplitude (see supplemental Fig. 4 , available at www.jneurosci.org as supplemental material). In these experiments, inhibitory transmission was left intact. Error bars indicate SEM. 
Table 1. Changes in action potential waveform parameters evoked by tetanization and by application of $\mathrm{K}$ channel antagonists, respectively.

\begin{tabular}{|c|c|c|c|c|c|}
\hline & $\mid \begin{array}{l}\text { Amplitude } \\
(\mathrm{mV})\end{array}$ & $\mathrm{AHP}(\mathrm{mV})$ & $\begin{array}{l}\text { Em after } \\
\text { spike (mV) }\end{array}$ & $\begin{array}{l}10 \%-90 \% \\
\text { (ms) }\end{array}$ & FWHM (ms) \\
\hline $\begin{array}{l}\text { Control before IP } \\
\text { Control after IP }\end{array}$ & $\begin{array}{l}91.6 \pm 5.3 \\
89.9 \pm 4.5\end{array}$ & $\begin{array}{l}-6.9 \pm 1.2 \\
-6.1 \pm 2.1\end{array}$ & $\left|\begin{array}{l}-49.6 \pm 1.6 \\
-48.4 \pm 1.6\end{array}\right| *$ & $\begin{array}{l}0.198 \pm 0.015 \\
0.186 \pm 0.015\end{array}$ & $\begin{array}{l}0.288 \pm 0.028 \\
0.276 \pm 0.022\end{array}$ \\
\hline $\begin{array}{l}\text { Before 4AP } \\
\text { Under 4AP } \\
\text { Under 4AP after IP }\end{array}$ & $\begin{array}{l}87.7 \pm 6.9 \\
88.3 \pm 3.2 \\
87.6 \pm 8.4\end{array}$ & $\left|\begin{array}{l}-4.9 \pm 1.6 \\
9.6 \pm 1.9 \\
10.6 \pm 3.2\end{array}\right| * \mid *$ & $\begin{array}{l}-52.0 \pm 2.3 \\
-54.1 \pm 2.1 \\
-54.4 \pm 2\end{array}$ & $\begin{array}{l}0.180 \pm 0.001 \\
0.190 \pm 0.009 \\
0.188 \pm 0.007\end{array}$ & $\left|\begin{array}{l}0.270 \pm 0.026 \\
0.435 \pm 0.039 \\
0.465 \pm 0.043\end{array}\right| *$ \\
\hline $\begin{array}{l}\text { Before HPTX } \\
\text { Under HPTX } \\
\text { Under HPTX after IP }\end{array}$ & $\begin{array}{l}76.1 \pm 5.5 \\
74.4 \pm 4.5 \\
75.3 \pm 5.4\end{array}$ & $\begin{array}{l}-7.1 \pm 1.5 \\
-6.4 \pm 1.4 \\
-6.8 \pm 1.4\end{array}$ & $\begin{array}{l}-59.9 \pm 1.3 \\
-57.4 \pm 3.1 \\
-58.8 \pm 2.8\end{array}$ & $\begin{array}{l}0.210 \pm 0.019 \\
0.220 \pm 0.017 \\
0.215 \pm 0.024\end{array}$ & $\begin{array}{l}0.320 \pm 0.040 \\
0.340 \pm 0.041 \\
0.335 \pm 0.045\end{array}$ \\
\hline $\begin{array}{l}\text { Before apamin } \\
\text { Under apamin } \\
\text { Under apamin after IP }\end{array}$ & \begin{tabular}{|c|}
$98.4 \pm 5.4$ \\
$98.8 \pm 4.1$ \\
$100.6 \pm 5.7$
\end{tabular} & $\begin{array}{l}-7.8 \pm 2.2 \\
-7.5 \pm 2 \\
-7.1 \pm 1.9\end{array}$ & $\left|\begin{array}{l}-51.9 \pm 1.3 \\
-50.2 \pm 1.3 \\
-49.9 \pm 1.5\end{array}\right| *$ & $\begin{array}{l}0.180 \pm 0.013 \\
0.175 \pm 0.014 \\
0.165 \pm 0.010\end{array}$ & $\begin{array}{l}0.220 \pm 0.018 \\
0.235 \pm 0.016 \\
0.230 \pm 0.115\end{array}$ \\
\hline
\end{tabular}

Parameters of the action potential waveform that were monitored are the peak amplitude, the AHP amplitude, the $10-90 \%$ rise time, the full width at half magnitude (FWHM), and the rate of postspike depolarization ( $E_{\mathrm{m}}$ measured $4.5-6$ $\mathrm{ms}$ after the spike peak). The table summarizes these parameters (see also Fig. 3B) under control conditions ( $n=5)$ and with 4-AP bath application $(n=11)$, heteropodatoxin-2 bath application ( $n=7$ ), and apamin bath application ( $n=15)$.

For comparison of the AHP changes reported here to those shown in Figure $1 B$, note that in the recordings summarized in this table, inhibition was left intact. IP indicates application of the intrinsic plasticity protocol (repeated current injection). All values are shown as mean \pm SEM.

justing the amplitude of the current steps and the amplitude of the hyperpolarizing bias currents. On average, there was no significant difference in the amplitudes of these currents between the control group and the drug application groups described here (current steps; control: $180.81 \pm 17.74 \mathrm{pA} ; n=15 ; 4-\mathrm{AP}: 160.0 \pm$ $26.64 \mathrm{pA} ; p=0.52 ; n=7$; HpTX-2: $150.0 \pm 32.56 \mathrm{pA} ; p=0.51$; $n=5$; apamin: $139.54 \pm 11.99 \mathrm{pA} ; p=0.09 ; n=11$; Student's $t$ test/holding currents; control: $-471.56 \pm 14.02 \mathrm{pA} ; n=15$; 4-AP: $-450.86 \pm 45.65 \mathrm{pA} ; p=0.57 ; n=7$; HpTX-2: $-384.0 \pm$ $36.69 \mathrm{pA} ; p=0.06 ; n=5$; apamin: $-527.18 \pm 29.38 \mathrm{pA} ; p=0.08$; $n=11$; Student's $t$ test) (supplemental Fig. 4 , available at www. jneurosci.org as supplemental material). Moreover, there was no significant correlation between the current step amplitude or holding current amplitude, respectively, and the intrinsic plasticity amplitude (current steps; control: $p=0.35$; 4-AP: $p=0.81$; HpTX-2: $p=0.16$; apamin: $p=0.54$; holding currents; control: $p=0.51$; 4 -AP: $p=0.99$; HpTX-2: $p=0.06$; apamin: $p=0.08$; Pearson test) (supplemental Fig. 4, available at www.jneurosci. org as supplemental material), excluding the possibility that differences in the occlusion experiments might be due to differences in the amplitude of either the current steps or the bias holding currents.

We next tested the effects of heteropodatoxin-2 (HpTX-2), a selective inhibitor of Kv4.2-mediated $I_{\mathrm{A}}$ currents. Bath application of HpTX-2 (100 nM) significantly enhanced the spike count $(187.1 \pm 8.6 \% ; n=7 ; p=0.00004)$ (Fig. 3E). Like 4-AP, HpTX-2 increased the action potential width (before: $0.32 \pm 0.04 \mathrm{~ms}$; after tetanization: $0.34 \pm 0.04 \mathrm{~ms} ; n=6 ; p=0.033$ ) (Fig. 3E, Table 1), but with HpTX-2 this effect was less pronounced. HpTX-2 application did not occlude excitability increases triggered by tetanic current injection $(165.1 \pm 12.9 \% ; n=6)$ (Fig. $3 F$ ) (as compared to $155.2 \pm 5.4 \% ; n=15)$ (Fig. $1 C)(p=0.88)$. These data show that Kv4.2-mediated $I_{\mathrm{A}}$ currents are not involved in Purkinje cell intrinsic plasticity.

Next, we examined the involvement of SK-type calciumdependent K channels in Purkinje cell intrinsic plasticity. In layer $\mathrm{V}$ pyramidal neurons, SK channels have been implicated in activity-dependent excitability increases (Sourdet et al., 2003). In Purkinje cells, SK channels have been shown to control spike firing (Edgerton and Reinhart, 2003; Womack and Khodakhah,
2003). Bath application of the SK-channel blocker apamin (3 nM) caused a pronounced increase in the spike count $(316.1 \pm 39.7 \%$; $n=15 ; p=0.00003$ ) (Fig. $3 G$ ), without changing the action potential width (before: $0.22 \pm 0.02 \mathrm{~ms}$; apamin: $0.24 \pm 0.02 \mathrm{~ms}$; $n=15 ; p=0.08$ ) (Fig. 3G, Table 1). However, following each action potential, the rate of depolarization toward spike threshold was enhanced in the presence of apamin. This effect was also observed under control conditions after tetanization (Fig. 3A, Table 1). Finally, after bath application of apamin, subsequent tetanization caused only a moderate increase in the spike count $(119.6 \pm 6.4 \% ; n=10 ; p=0.008)$ (Fig. $3 H)$, which was significantly lower than that observed under control conditions $(155.2 \pm 5.4 \% ; n=15 ; p=0.009)$. This partial occlusion effect after apamin bath application suggests that a downregulation of SK-type K currents contributes to Purkinje cell intrinsic plasticity. Finally, we tested the BK-type calcium-dependent K channel blocker iberiotoxin. BK channels control the spread of calcium spikes in Purkinje cell dendrites (Rancz and Häusser, 2006), and might therefore be involved in excitability control as well. While bath application of iberiotoxin $(50 \mathrm{nM})$ enhanced the spike count (184.1 $\pm 30.2 \% ; n=7 ; p=0.02$ ) (supplemental Fig. $5 A$, available at www.jneurosci.org as supplemental material), it did not occlude intrinsic plasticity after current injection $(159.9 \pm 19.6 \%$; $n=6$; $p=0.80$ ) (supplemental Fig. $5 B$, available at www.jneurosci.org as supplemental material), which rules out the possibility that BK-type K channels are involved in intrinsic plasticity.

These experiments show that the form of intrinsic plasticity described here is at least partially mediated by a downregulation of SK-type calcium-dependent K channels. Of the three types of apamin-sensitive SK channel subunits (SK1-SK3), only SK2 channels are expressed in rat Purkinje cells, but their levels have been shown to decline during the first 3 postnatal weeks (Cingolani et al., 2002). In contrast to rats, mice have been shown to express SK2 channels in the adult Purkinje cell layer (Sailer et al., 2004). As our patch-clamp recordings were obtained from up to 4 -weekold rats, we examined whether SK2 channels are indeed expressed in young adult and adult rat Purkinje cells as suggested by recordings from our laboratory and others (Womack and Khodakhah, 2003), and performed immunostainings using antibodies directed against the C-terminal domain of the SK2 channel sub- 

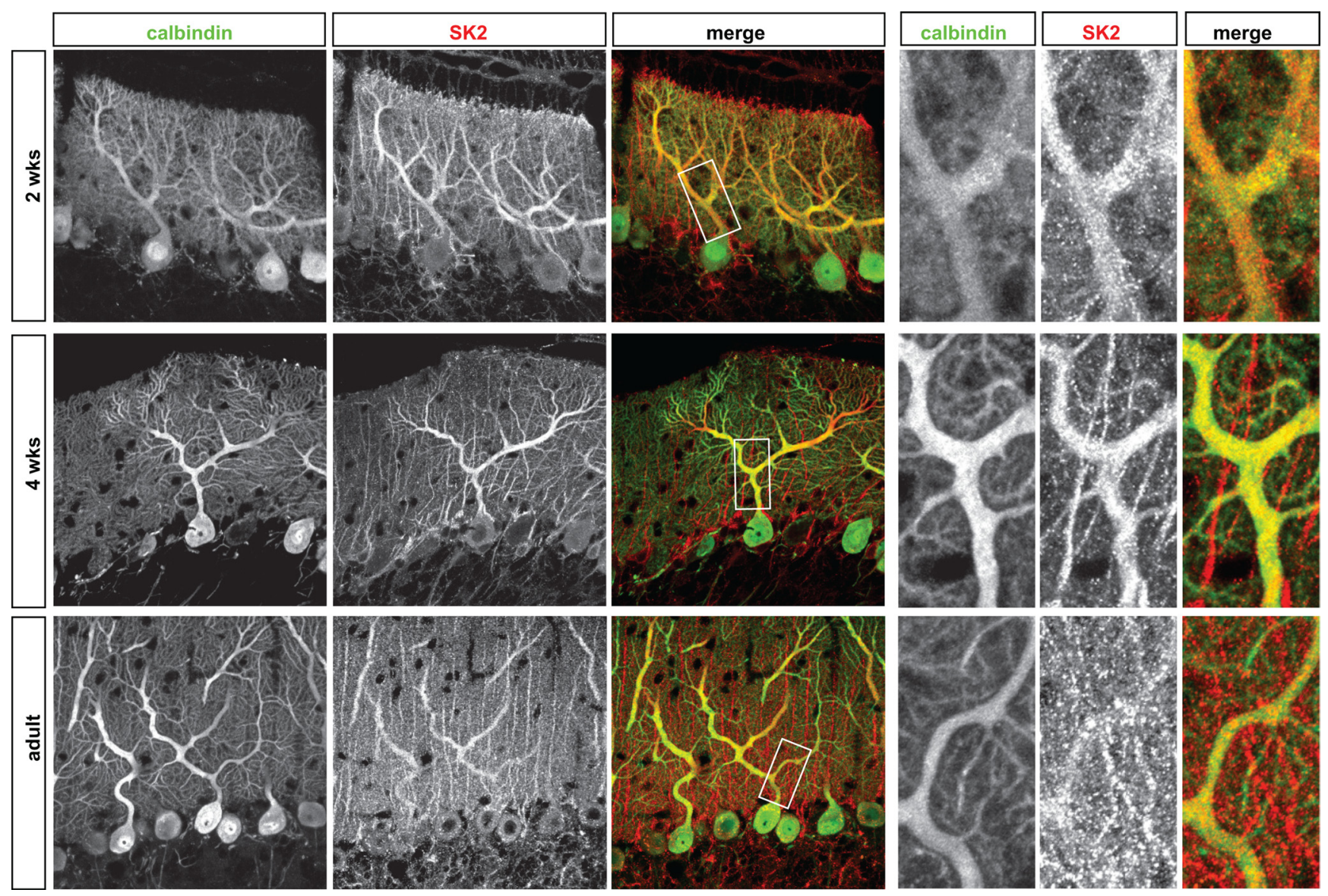

Figure 4. SK2 channel immunostaining. Anti-SK2-channel (red) and anti-calbindin (green) antibody stainings of cerebellar sections obtained from 2 week-old (top row), 4 week-old (middle row), and adult (bottom row) rats show SK2-staining in Purkinje cell dendrites and throughout the molecular layer. Right side, Enlarged views taken from the areas indicated by white boxes on the left.

unit, and the Purkinje cell-specific marker calbindin (Fig. 4; for antibody specificity, see supplemental Fig. 6, available at www.jneurosci.org as supplemental material). Cerebellar sections obtained from 2-week-old rats (top row), 4-week-old rats (middle row), and adult rats (3-4 months; bottom row) indicated presence of SK2 channel subunits at all three ages, which overlapped with the Purkinje cell-specific calbindin staining. Throughout all ages, but particularly in the adult sections, we also observed SK2 channel staining around granule cell bodies, and in the molecular layer. These immunohistochemical data show that SK2 channels are expressed in Purkinje cells during development and after maturation; therefore, SK2 channels can be involved in the type of Purkinje cell excitability alterations described here.

What molecular events are involved in intrinsic plasticity upstream of the functional downregulation of SK2 channels described above? We first examined whether intrinsic plasticity depends on dendritic calcium signaling, and the activation of protein phosphatases $1,2 \mathrm{~A}$, and $2 \mathrm{~B}$, which have been implicated in PF-LTP (Coesmans et al., 2004; Belmeguenai and Hansel, 2005). Intrinsic plasticity was blocked when the calcium chelator BAPTA $(20 \mathrm{~mm})$ was added to the pipette saline $(86.9 \pm 13.6 \%$; $n=11 ; p=0.37)$ (Fig. $5 A$ ), suggesting that calcium is a prerequisite for the induction process. In the absence of tetanization, BAPTA application alone transiently enhances the spike rate, but has no lasting effect on Purkinje cell excitability $(n=10)$ (for wash-in control recordings for all drug experiments shown in Figs. 5 and 6, see supplemental Fig. 7, available at www.jneurosci. org as supplemental material).
When the PP1/2A inhibitor microcystin LR was added to the pipette saline $(10 \mu \mathrm{M})$, the current injection protocol failed to enhance the spike count $(105.5 \pm 20.8 \% ; n=7 ; p=0.80$ ) (Fig. $5 B)$. Similarly, bath application of the PP1/2A inhibitor okadaic acid $(1 \mu \mathrm{M})$ blocked intrinsic plasticity $(108.8 \pm 4.2 \% ; n=6 ; p=$ 0.064 ) (Fig. $5 B$ ). When the PP2B inhibitor cyclosporin A was bath applied $(100 \mu \mathrm{M})$, the spike count was even decreased (55.6 \pm $10.1 \% ; n=8 ; p=0.00317$ ) (Fig. $5 B$ ). These results suggest that Purkinje cell intrinsic plasticity shares the requirement for PP1/2A and PP2B activation with PF-LTP. The PP2B dependence of intrinsic plasticity was confirmed using mice, in which PP2B was selectively knocked out in Purkinje cells (L7-PP2B mice). In wild-type mice, application of the current injection protocol enhanced the spike rate (138.9 $\pm 10.2 \% ; n=16 ; p=0.009)$ (Fig. $5 C$ ). Intrinsic plasticity was absent in L7-PP2B knock-out mice (89.7 $\pm 9.4 \% ; n=9 ; p=0.40$ ) (Fig. 5C). Conversely, PP2B activation can enhance the spike count: when active PP2B was added to the pipette saline $(5 \mu \mathrm{g} / \mathrm{ml})$, the spike count increased significantly $(149.1 \pm 15.2 \% ; n=11 ; p=0.00423)$ (supplemental Fig. $8 \mathrm{~A}$, available at www.jneurosci.org as supplemental material). Subsequently, intrinsic plasticity was occluded (101.5 \pm $9.0 \% ; n=8 ; p=0.87$ ) (supplemental Fig. $8 B$, available at www. jneurosci.org as supplemental material). The phosphatase dependence of intrinsic plasticity is not restricted to excitability increases triggered by application of the current step protocol. Likewise, application of the $1 \mathrm{~Hz} \mathrm{PF}$ stimulation protocol failed to cause excitability changes in the presence of the PP1/2A inhibitor okadaic acid ( $1 \mu \mathrm{M} ; 105.4 \pm 5.8 \% ; n=8 ; p=0.37)$ (Fig. $5 D)$ or 

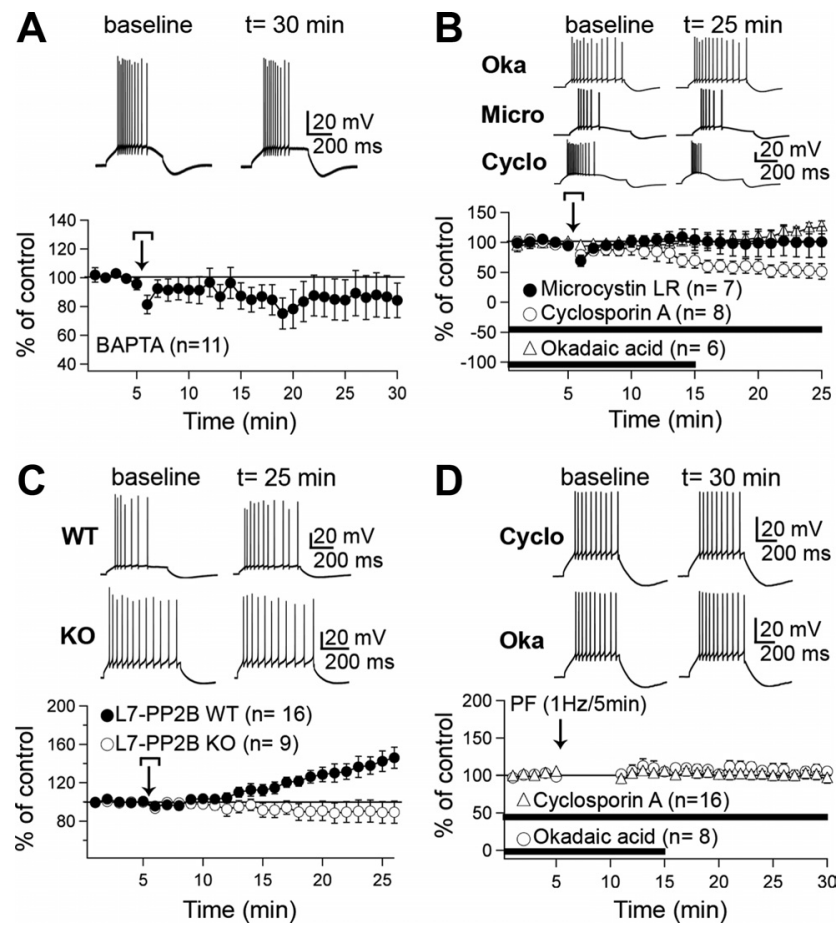

Figure 5. Purkinje cell intrinsic plasticity depends on calcium signaling, and activation of protein phosphatases 1, 2A, and $2 B$. $A$, Intrinsic plasticity was blocked when BAPTA (20 mM) was added to the pipette saline $(n=11)$. $\boldsymbol{B}$, Likewise, the current injection protocol was ineffective in the presence of the PP1/2A inhibitormicrocystin LR (10 $\mu$; closed circles; $n=7)$, the PP1/2A inhibitor okadaic acid (1 $\mu \mathrm{m}$; open triangles; $n=6)$, and the PP2B inhibitor cyclosporin A (100 $\mu \mathrm{m}$; open circles; $n=8)$. C, Intrinsic plasticity was intact in slices prepared from wild-type mice (closed circles; $n=16$ ), but was inhibited in slices prepared from L7-PP2B knock-out mice (open circles; $n=9$ ). $\boldsymbol{D}$, Application of the $1 \mathrm{~Hz}$ PFstimulation protocol failed to induce excitability changes in the presence of okadaic acid (1 $\mu \mathrm{M}_{\text {; }}$ open circles; $n=8$ ) and cyclosporin A (100 $\mu \mathrm{m}$; open triangles; $n=16)$. Error bars indicate SEM.

in the presence of the PP2B inhibitor cyclosporin A $(100 \mu \mathrm{M}$; $98.3 \pm 4.7 \% ; n=16 ; p=0.72$ ) (Fig. $5 D$ ). These data suggest that intrinsic excitability changes triggered by current injection or PF tetanization share the same induction mechanism, which involves an activation of protein phosphatases 1, 2A, and 2B.

At $\mathrm{PF}$ synapses, bidirectional synaptic plasticity is governed by a molecular switch mechanism involving PP1, 2A, and 2B as well as the $\alpha$ isoform of calcium/calmodulin-dependent kinase II ( $\alpha$ CaMKII) (Jörntell and Hansel, 2006). To examine whether $\alpha \mathrm{CaMKII}$ is involved in intrinsic plasticity, we applied the current injection protocol to Purkinje cells in slices prepared from $\alpha$ CaMKII knock-out mice (Elgersma et al., 2002), and wild-type controls. Intrinsic plasticity was observed in both wild-type mice $(246.0 \pm 18.6 \% ; n=7 ; p=0.00001)$ (Fig. $6 A)$ and in $\alpha$ CaMKII knock-out mice (240.4 $\pm 22.0 \% ; n=12 ; p=0.00001)$ (Fig. $6 A$ ). There was no statistical difference between these two groups $(p=0.87)$, suggesting that $\alpha \mathrm{CaMKII}$ is not required to enhance excitability. It has recently been shown that the surface expression of SK2 channels is regulated by cAMP-dependent protein kinase (PKA) (Ren et al., 2006), which has also been implemented in hippocampal intrinsic plasticity (Oh et al., 2009; Rosenkranz et al., 2009). When the PKA inhibitor KT5720 (30 $\mu \mathrm{M})$ was applied to the bath, we observed a strong reduction in excitability increases $(135.9 \pm 10.5 \% ; n=14 ; p=0.00276)$ (Fig. $6 B)$. At a higher concentration $(60 \mu \mathrm{M})$, KT5720 blocked intrinsic plasticity, and even caused a slight reduction in excitability after tetanization ( $80.6 \pm 5.2 \% ; n=12 ; p=0.00179$ ) (Fig. $6 B$ ). At both concentrations, the reduction in the intrinsic plasticity amplitude
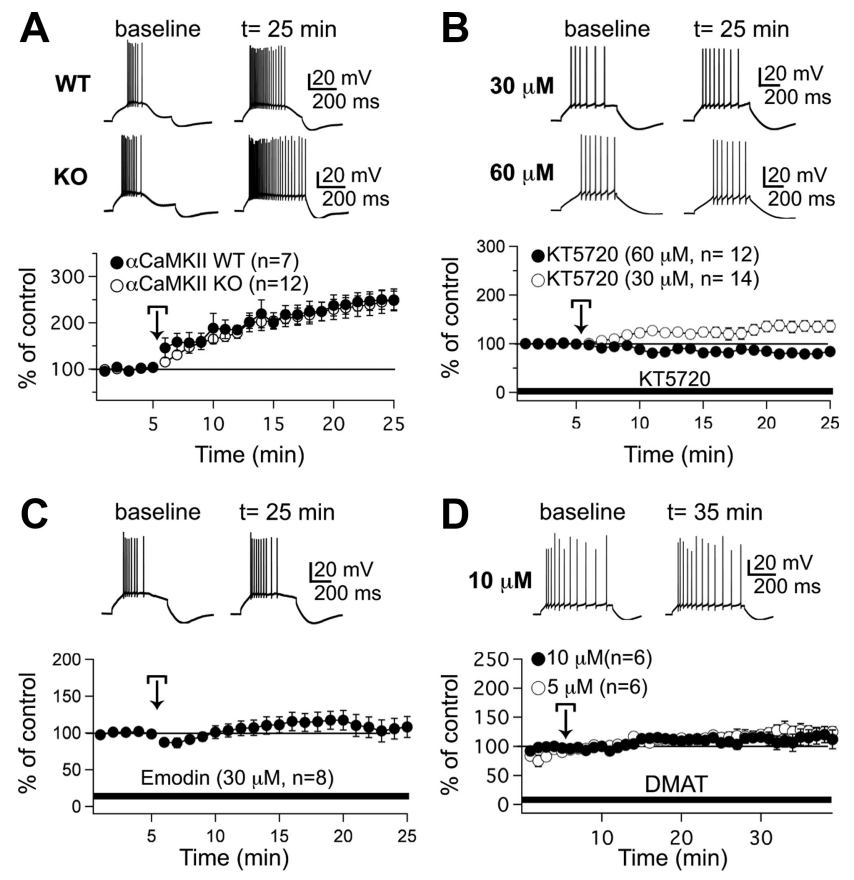

Figure 6. Involvement of protein kinases in Purkinje cell intrinsic plasticity. $\boldsymbol{A}$, Intrinsic plasticity was observed in $\alpha$ CaMKII knock-out mice (open circles; $n=12$ ) and wild-type controls (closed circles; $n=7$ ). $\boldsymbol{B}$, Bath application of the PKA inhibitor KT5720 at $30 \mu \mathrm{m}$ (open circles; $n=14$ ) and $60 \mu \mathrm{m}$ (closed circles; $n=12$ ) affected intrinsic plasticity. C, Excitability increases were prevented by bath application of the CK2 inhibitor emodin (30 $\mu \mathrm{m} ; n=8)$. $\boldsymbol{D}$, Intrinsic plasticity was also blocked by bath application of the CK2 inhibitor DMAT at $5 \mu \mathrm{m}$ (open circles; $n=6$ ) and $10 \mu \mathrm{m}$ (closed circles; $n=6$ ). Error bars indicate SEM.

was significant ( $30 \mu \mathrm{M}: p=0.00026 ; 60 \mu \mathrm{M}: p=0.00012$; MannWhitney $U$ test), which shows that PKA activation is required to enhance excitability. We finally examined the involvement of casein kinase 2 (CK2) in intrinsic plasticity. CK2 is a constitutively active enzyme (Bildl et al., 2004) that phosphorylates SK2associated calmodulin and reduces the calcium sensitivity of SK2 channels (Allen et al., 2007). Intrinsic plasticity was blocked in the presence of the CK2 inhibitor emodin $(30 \mu \mathrm{M} ; 106.9 \pm$ $12.8 \% ; n=8 ; p=0.62$ ) (Fig. $6 C$ ). As in wash-in control experiments emodin application affected the spike rate in the absence of tetanization (supplemental Fig. $7 F$, available at www.jneurosci. org as supplemental material), we also used the more selective CK2 inhibitor 2-dimethylamino-4,5,6,7-tetrabromo- $1 \mathrm{H}$-benzimidazole (DMAT). In the presence of DMAT, intrinsic plasticity was blocked as well (DMAT; $5 \mu \mathrm{M}: 119.7 \pm 6.3 \% ; n=6 ; p=$ $0.023 ; 10 \mu \mathrm{M}: 113.5 \pm 9.8 \% ; n=6 ; p=0.30$ ) (Fig. $6 D$ ), suggesting that active CK2 is required for intrinsic plasticity.

\section{Purkinje cell intrinsic plasticity does not affect DCN spike rates}

Under physiological conditions, Purkinje cells are spontaneously active and fire simple spikes at 30-80 Hz (Simpson et al., 1996). In our recordings from spontaneously active Purkinje cells summarized in Figure 2, we observed background spike frequencies of $\sim 40 \mathrm{~Hz}$ in vivo and $\sim 30 \mathrm{~Hz}$ in vitro, respectively. Under various recording conditions both in vivo and in vitro, the spontaneous background spike frequency was enhanced when intrinsic plasticity protocols were applied (Fig. 2). These results show that intrinsic plasticity can increase the rate of Purkinje cell pacemaker activity, which is largely of intrinsic origin and persists when glutamatergic transmission is blocked (Häusser and Clark, 
A

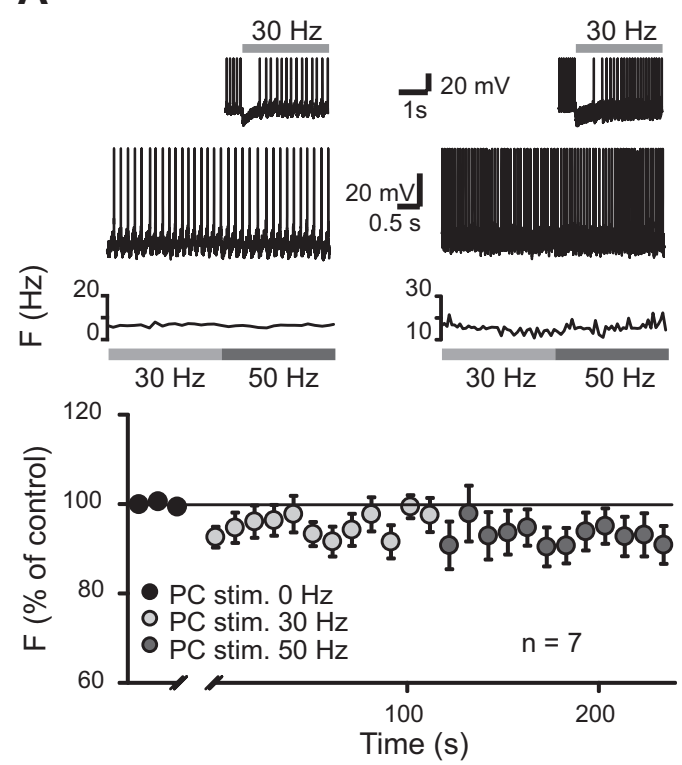

B
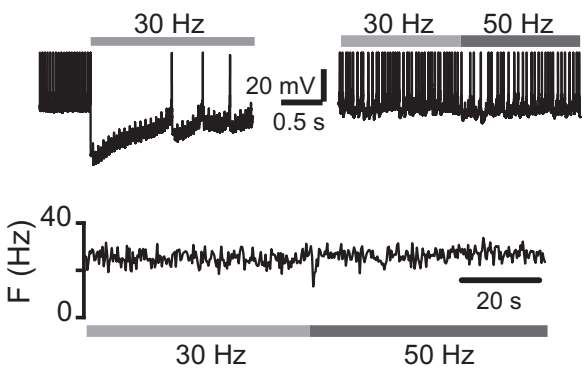

Control IPSP

Mean firing frequency

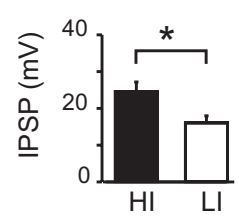

C

Averaged IPSPs

$30 \mathrm{~Hz}$ $50 \mathrm{~Hz}$

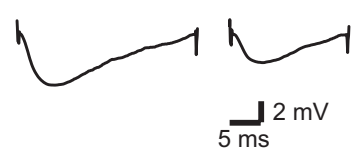

Averaged IPSPs
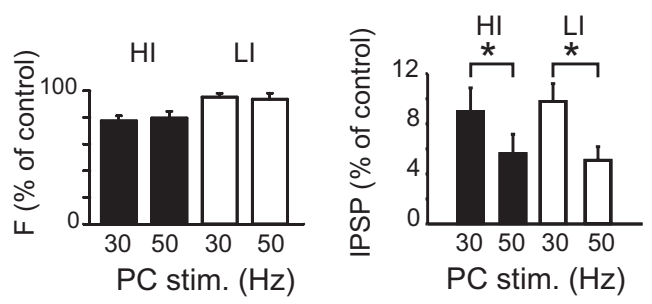

Figure 7. Intrinsic plasticity-associated changes in the spontaneous Purkinje cell spike rate do not affect the tonic spike rate of DCN neurons. $A$, Bottom, the spike frequency of DCN neurons ( $F)$ remained stable when the increase in Purkinje cell spike rates was mimicked by a switch from 30 to $50 \mathrm{~Hz}$ stimulation of Purkinje cell axons $(n=7$; values for the onset of $30 \mathrm{~Hz}$ activation are not depicted). Top, Two example recordings. The insets show the effect of a switch from 0 to $30 \mathrm{~Hz}$ stimulation of the inhibitory synapses. $\boldsymbol{B}$, Top, Example recordings using a higher stimulus intensity. Bottom, Increasing the stimulus intensity resulted in larger amplitudes of control IPSPs $(0.1 \mathrm{~Hz}$, left), but the effect of tonic stimulation at 30 and $50 \mathrm{~Hz}$ on the firing rate of DCN neurons was similar using high ( $\mathrm{Hl} ; n=8$ ) or low intensities (Ll; $n=7$ ). C, Bottom, At both high and low stimulus intensities, IPSP amplitudes were reduced to a larger degree at $50 \mathrm{~Hz}$ than at $30 \mathrm{~Hz}$ stimulation (averaged over 1 min before and after the frequency switch). Top, Example traces illustrating averaged IPSPs. The traces were taken from the same recording shown in $\boldsymbol{B}$. Error bars indicate SEM. ${ }^{*} p<0.05$.

1997), thus conveying little information on the activity state of synaptic inputs. Purkinje cells form inhibitory synapses with their DCN target cells (Ito, 1984), which on their own are spontaneously active (Jahnsen, 1986). We thus examined whether the spontaneous discharge rate of DCN neurons was affected by the enhanced background spike rate of Purkinje cells. Whole-cell patch-clamp recordings in current-clamp mode were obtained from DCN neurons in vitro, and Purkinje cell axons were stimulated in the white matter (Pedroarena and Schwarz, 2003). Two different sets of experiments were performed: In a first set of experiments, the resulting IPSPs $(16.0 \pm 1.9 \mathrm{mV} ; n=7)$ consistently evoked a pause in spontaneous DCN firing (Fig. 7A). In the second set of experiments, higher stimulus intensities were used to examine whether an enhanced inhibitory input (reflecting a higher number of simultaneously active Purkinje cells, $24.6 \pm 2.6$ $\mathrm{mV} ; n=8 ; p=0.017$; Mann-Whitney $U$ test) affects DCN neurons more efficiently (Fig. 7B). Purkinje cell spontaneous activity was mimicked by protracted (2-4 min) $30 \mathrm{~Hz}$ activation of Purkinje cell axons, allowing the synapses to reach stationary levels of short-term depression (Telgkamp and Raman, 2002; Pedroarena and Schwarz, 2003). Intrinsic plasticity was simulated by a switch from 30 to $50 \mathrm{~Hz}$ activation. These frequencies were selected to mimic the increase in the spike rate observed following application of intrinsic plasticity protocols in vitro (Fig. $2 C-F$ ). Activation at $30 \mathrm{~Hz}$ resulted first in a transient cessation of DCN firing [Fig. $7 A$ (insets), $B$ (top)], followed by discharge at a reduced rate. However, there was no further reduction upon switch to $50 \mathrm{~Hz}$, using either low or high stimulus intensities (low $30 \mathrm{~Hz}$ : $95.2 \pm$ 2.8\%; low $50 \mathrm{~Hz}$ : $93.6 \pm 4.6 \% ; n=7 ; p=0.68$; high $30 \mathrm{~Hz}: 77.4 \pm$ $3.8 \%$; high $50 \mathrm{~Hz}$ : $79.5 \pm 5.0 \% ; n=8 ; p=0.46$; Wilcoxon signed-rank test) (Fig. 7). The observation that the DCN spike rate was not affected by an enhanced frequency of inhibitory Purkinje cell output is possibly explained by the filtering properties of synapses depressed to stationary levels (Pedroarena and
Schwarz, 2003), since DCN neurons are affected by the frequency of inhibitory inputs if these are activated for shorter periods (Telgkamp and Raman, 2002), or if depression is lacking (Gauck and Jäger, 2000). To assess the degree of depression, IPSPs were averaged over a $1 \mathrm{~min}$ period before and after the switch from 30 to $50 \mathrm{~Hz}$ stimulation. At $30 \mathrm{~Hz}$ stimulation, IPSPs were reduced to $8.8 \pm 1.9 \%$ at high stimulus intensity $(n=8)$, and to $9.7 \pm$ $1.4 \%$ at low stimulus intensity $(n=7)$ (Fig. $7 C$ ). The strong depression at $30 \mathrm{~Hz}$ stimulation correlates with the moderate effect of tonic Purkinje cell activation on the firing rate of DCN neurons. At $50 \mathrm{~Hz}$ stimulation, IPSPs were further reduced to almost half of the levels found at $30 \mathrm{~Hz}: 5.6 \pm 1.5 \%$ at high stimulus intensity $(n=8)$, and to $5.1 \pm 1.1 \%$ at low stimulus intensity $(n=7)$ (Fig. 7C). At both intensities, this further reduction in IPSP amplitudes upon switch from 30 to $50 \mathrm{~Hz}$ stimulation was significant (high intensity: $p=0.022$; low intensity: $p=0.016$; Wilcoxon signed-rank test) and present in all neurons examined. Depression of IPSPs during a train has previously been described for shorter stimulus trains in the DCN (Telgkamp and Raman, 2002, Pedroarena and Schwarz, 2003). Together, our DCN recordings suggest that the enhanced frequency of Purkinje cell pacemaker activity, which is associated with intrinsic plasticity, does not have a direct effect on the spontaneous spike rate of DCN neurons. The results also point to the stronger depression of inhibitory Purkinje cell-DCN neuron synapses as a mechanism to counterbalance the inhibitory effect of enhanced IPSP frequencies.

Intrinsic excitability changes affect the impact of PF signaling What then are the functional consequences of alterations in Purkinje cell excitability? Does intrinsic plasticity affect the inputoutput function of Purkinje cells? It has previously been shown for weak PF inputs that the number of evoked spikes linearly reflects synaptic input strength (Walter and Khodakhah, 2006; Mittmann and Häusser, 2007). To examine whether intrinsic 
A
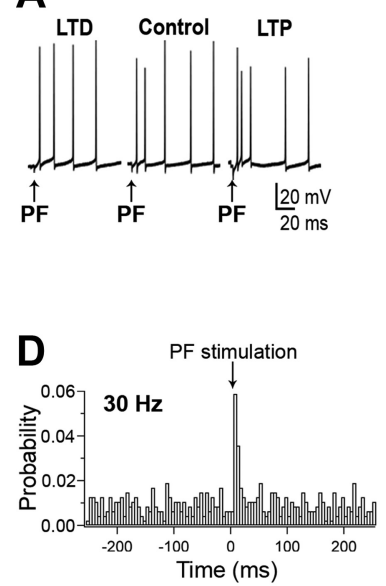

$\mathbf{F}$

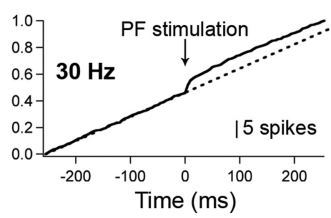

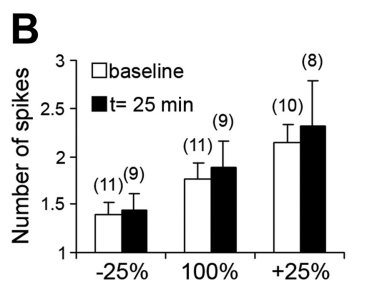

C
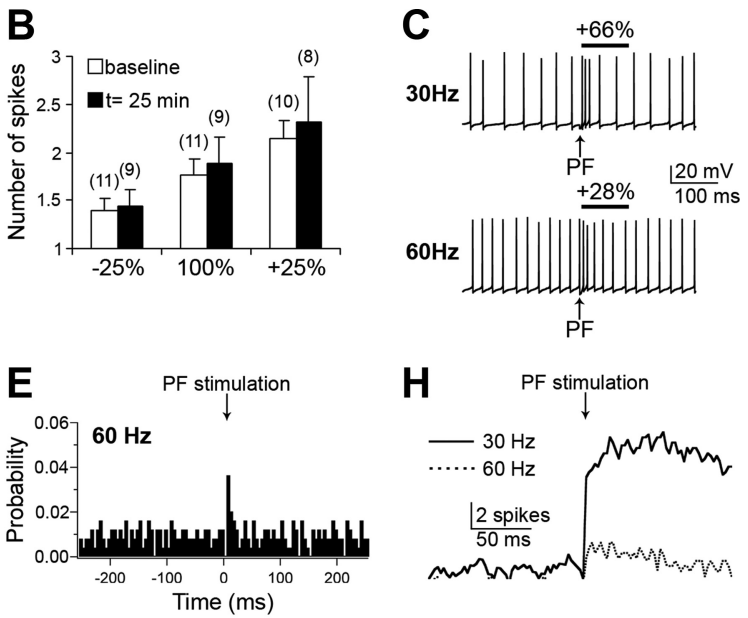

G

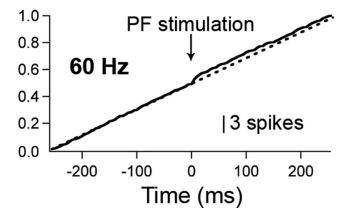

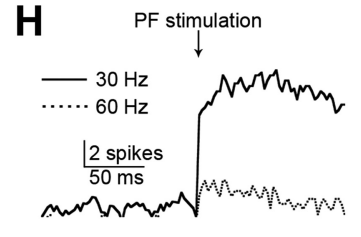

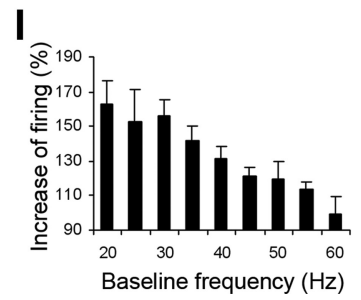

Figure 8. Purkinje cell intrinsic plasticity lowers the impact of PF signaling. $\boldsymbol{A}$, Intrinsic plasticity does not affect the synaptic input - output curve of Purkinje cells. PF stimulus strength was varied by $\pm 25 \%$, which approximately corresponds to amplitude changes seen after LTP and LTD induction. $\boldsymbol{B}$, The linear relationship between stimulus strength and the number of evoked spikes was not significantly affected by intrinsic plasticity $(n=8-9$; paired Student's $t$ test; $p>0.05$; the number of spikes evoked at all three stimulus strengths was compared before and after inducing intrinsic plasticity). The spike count includes all spikes that occurred at elevated frequency after PF stimulus onset during a $100 \mathrm{~ms}$ time window. The number of recordings is indicated in the brackets. C, When the background spike rate was enhanced from $30 \mathrm{~Hz}$ (top) to $60 \mathrm{~Hz}$ (bottom), the net increase in spike numbers evoked by constant PF stimulation was lowered. $\boldsymbol{D}, \boldsymbol{E}$, PSTHs calculated from PF responses at background spike frequencies of $30 \mathrm{~Hz}$ (D) and $60 \mathrm{~Hz}(\boldsymbol{E}) . \boldsymbol{F}, \mathbf{G}$, Cumulative spike probabilities at $30 \mathrm{~Hz}(\boldsymbol{F})$ and $60 \mathrm{~Hz}(\boldsymbol{G})$. The dotted line represents a fit to the baseline. $\boldsymbol{H}$, Corrected cumulative spike probabilities after subtraction of the baseline fit at $30 \mathrm{~Hz}$ and $60 \mathrm{~Hz}$. I, Inverse relationship between the spike rate and the net increase in spike firing, which was calculated from $100 \mathrm{~ms}$ time windows before and after PF stimulation $(n=7)$. The analysis shown in $\boldsymbol{D}-\boldsymbol{H}$ is based on 477 spikes $(30 \mathrm{~Hz})$ and 247 spikes $(60 \mathrm{~Hz})$, respectively $(n=7)$. Error bars indicate SEM.

plasticity affects the input-output curve of Purkinje cells, we allowed the cells to spontaneously discharge and counted the number of spikes evoked by PF stimulation. We then mimicked LTD and LTP conditions by adjusting the stimulus strength to $\pm 25 \%$ of the control level (Fig. $8 \mathrm{~A}$ ). We observed a linear relationship between stimulus strength and the number of evoked spikes, but the dynamic range was very limited: varying the stimulus strength over a range of $50 \%$ led to variations in the number of evoked spikes ranging from one to four spikes $(n=11)$ (Fig. $8 B$ ). This observation suggests a limited control of the spike output of Purkinje cells by LTD and LTP, respectively. After repeated current injection, the spike output in all three intensity groups was slightly enhanced, but this trend did not reach statistical significance $(n=8-9 ;-25 \%: p=0.90$; control: $p=0.53 ;+25 \%$ : $p=0.60$; paired Student's $t$ test) (Fig. $8 B$ ), suggesting that intrinsic plasticity has at most a weak effect on the spike output. We obtained similar results when analyzing the spike frequency, rather than the number of evoked spikes. We calculated increases in the spike frequency resulting from PF stimulation as the ratio of the frequency recorded from 3 spikes right after stimulation to the frequency recorded before. Increasing stimulus strength enhanced this frequency ratio $(-25 \%: 1.5 \pm 0.1 ; n=11$; control: $2.2 \pm$ $0.3 ; n=11 ;+25 \%: 2.9 \pm 0.4 ; n=10)$. After tetanization, these ratios were not significantly changed $(-25 \%: 1.7 \pm 0.4 ; p=0.48 ; n=9$; control: $2.3 \pm 0.5 ; p=0.33 ; n=9 ;+25 \%$ : $2.8 \pm 0.6 ; p=0.83 ; n=8$; paired Student's $t$ test). In these experiments, changes in background spiking were prevented by injection of bias currents.

To examine whether the intrinsic plasticity-associated increase in the background spike rate itself affects PF signaling, we performed the opposite experiment and injected bias currents to vary the background spike rate (mimicking intrinsic plasticity), while the PF stimulus strength was kept constant (Fig. 8C). Alterations in the spike rate ranging from 30 to $60 \mathrm{~Hz}$ did not result in changes in the immediate PF response (Fig. $8 \mathrm{C}$ ), but the enhanced background spike rate lowered the signal-to-noise ratio and thus lowered the transient $\mathrm{PF}$-evoked net increase in spike firing $(n=7)$ (Fig. $8 C-I)$. These data are in line with a previous report demonstrating an inverse relationship between Purkinje cell background spike rates and PF readout (McKay et al., 2007), and suggest that as a consequence of the activity-dependent plasticity described here, the impact of PF signaling is actually reduced despite of an increase in excitability.

To directly quantify the number of additional spikes that is attributable to PF stimulation at background spike frequencies of 30 and $60 \mathrm{~Hz}$, respectively, we adopted an analysis method that provides an estimate of the impact of a given synaptic input on the spike output of neurons (Mittmann and Häusser, 2007). We first calculated the PSTH of the PF response patterns (Fig. $8 D, E$ ), and plotted the cumulative spike probability (Fig. $8 F, G$ ). Subsequently, we fitted a line to the baseline period, which was then subtracted from the cumulative probability trace. The corrected cumulative spike probability traces (Fig. $8 H$ ) indicate the number of spikes that were caused by PF stimulation. The increase in spike firing attributable to PF stimulation at a background spike frequency of 30 $\mathrm{Hz}$ is more pronounced than that observed at a background spike frequency of $60 \mathrm{~Hz}$ (Fig. $8 \mathrm{H}$ ), suggesting that the impact of synaptic signaling is higher at a lower tonic background spike frequency. Over several background frequencies tested, the increase in firing caused by PF stimulation (as a percentage; calculated from $100 \mathrm{~ms}$ time periods before and after PF stimulation) decreased with increasing spike frequencies (Fig. 8C,I).

Intrinsic plasticity enhances dendritic calcium signaling, but lowers the probability for subsequent LTP induction

Synaptic gain control is typically associated with LTP and LTD. To examine whether intrinsic plasticity interferes with synaptic plasticity, we tested whether the LTP induction probability was altered after previous enhancement of intrinsic excitability. In these experiments, PF-EPSPs and the spike count were monitored within the same sweeps (Fig. 9A). Application of the current injection protocol $(5 \mathrm{~Hz}, 3 \mathrm{~s})$ enhanced the spike count 


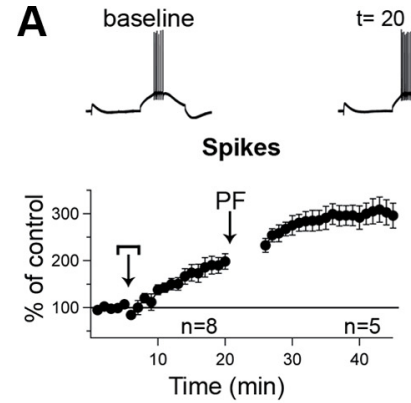

B
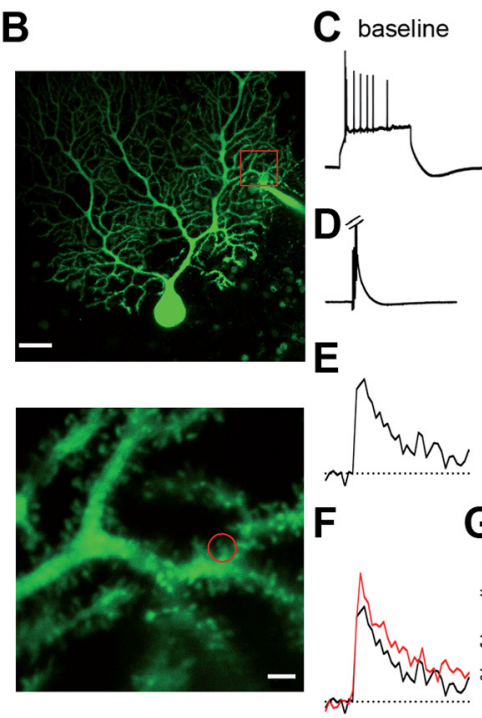
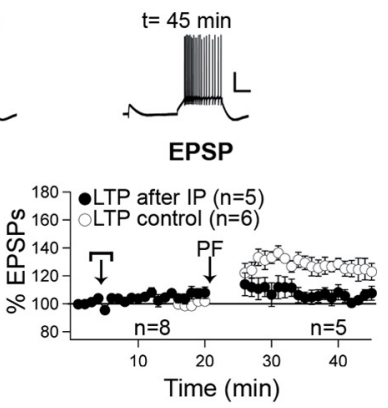

post-tetanus
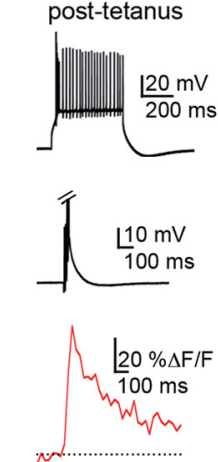

$\underbrace{200} \underbrace{\mathbf{G}_{0}^{\infty}}_{0}$

H

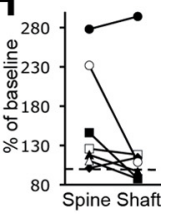

Figure 9. Intrinsic plasticity enhances spine calcium signaling, but blocks subsequent LTP induction. $A$, PF-EPSPs (right) and the spike count (left) were monitored after tetanic current injection $(n=8)$ and after subsequent application of the $1 \mathrm{~Hz}$ PF tetanization protocol $(n=5)$. LTP induction was blocked after previous application of the intrinsic plasticity protocol (black circles; $n=5$ ). In contrast, LTP was induced by PF stimulation, when intrinsic plasticity was not previously triggered (white circles; $n=6$ ). Top, Traces show EPSPs and depolarization-evoked spikes under baseline conditions (left), after application of the intrinsic plasticity protocol (middle), and after application of the PF-LTP protocol (right). In all recordings shown in $\boldsymbol{A}$, inhibition was left intact. Calibration: $20 \mathrm{mV}, 200 \mathrm{~ms}$. $\boldsymbol{B}-\boldsymbol{H}$, Confocal calcium imaging experiments reveal an increase in spine calcium transients. $\boldsymbol{B}$, Top, Purkinje cell filled with the fluorescent calcium indicator Oregon Green BAPTA-2 (200 $\mu \mathrm{m})$. Scale bar, $20 \mu \mathrm{m}$. Bottom, Enhanced view of the area marked by the red box in the top image. The red circle indicates the region of interest. Scale bar, $2 \mu \mathrm{m}$. C, The spike count was monitored before (left) and after tetanization (right). $\boldsymbol{D}$, Calcium transients were evoked by $100 \mathrm{~Hz}$ PF stimulation (4 pulses). PF responses are shown before (left) and after tetanization (right). $\boldsymbol{E}$, Calcium transients evoked by the PF responses shown in $\boldsymbol{D}$. The traces represent averages of 3 calcium transients. $\boldsymbol{F}$, An overlay of the calcium transients reveals enhanced calcium signaling. $\mathbf{G}$, Bar graph showing averaged changes in the area under the curve (left) and peak of calcium transients (middle), as well as the spike count (right). These values represent averages taken during a 12 min period following tetanization ( $n=7)$. $\boldsymbol{H}$, Comparison of calcium transient changes (area under the curve) in spines and associated shaft regions $(n=7)$. Error bars indicate SEM.

$(187.5 \pm 18.1 \%, t=15-20 \min ; n=8 ; p=0.00188)$ (Fig. $9 A)$, but did not affect the EPSP amplitude (106.1 $\pm 3.4 \% ; n=8 ; t=$ 15-20 min; $p=0.12$ ) (Fig. 9A). Subsequently, we applied the PF-LTP protocol $(1 \mathrm{~Hz}, 5 \mathrm{~min})$ to test whether intrinsic plasticity affects LTP induction. Application of the $1 \mathrm{~Hz}$ PF stimulation protocol further enhanced the spike count $(302.4 \pm 25.9 \% ; n=$ $5 ; t=40-45 \mathrm{~min} ; p=0.00133$ ) (Fig. $9 A$ ). However, when intrinsic plasticity was triggered first, LTP could not be induced anymore by subsequent $1 \mathrm{~Hz}$ PF stimulation (104.5 $\pm 3.4 \%$; $n=5$; $t=40-45$ min; $p=0.26$ ) (Fig. $9 A$ ). This observation likely reveals a metaplastic interaction rather than a run-down of the
LTP probability (known from LTD induction), because in control experiments, LTP could be observed after an equally long (20 $\min$ ) baseline period $(121.3 \pm 6.4 \% ; n=11 ; p=0.0079)$ (supplemental Fig. 9, available at www.jneurosci.org as supplemental material). The difference in EPSP amplitude changes monitored after (1) the application of the LTP protocol alone and (2) application of the LTP protocol following previous application of the current injection protocol was statistically significant (MannWhitney $U$ test; $p=0.0351$ ). For comparison, LTP induced after a shorter baseline period of $5 \mathrm{~min}$ amounted to $124.5 \pm 6.4 \%$ $(n=6 ; p=0.01$; last $5 \mathrm{~min}$ ) (Fig. $9 A$; note that an extended version of this LTP graph is shown in Fig. $1 E$ ). There was no statistical difference between the LTP amplitudes reached after baseline periods of $5 \mathrm{~min}$ and $20 \mathrm{~min}$, respectively (Mann-Whitney $U$ test; $p=0.45$ ). In these experiments, intrinsic plasticity was first triggered in the absence of synaptic alterations (nonsynaptic induction protocol) to be able to examine how intrinsic plasticity as an isolated phenomenon affects the LTP induction probability ( $1 \mathrm{~Hz}$ PF protocol). The results suggest that intrinsic plasticity subsequently lowers the LTP probability. An implication of these findings is that activated PF synapses can undergo both LTP and intrinsic plasticity, with the latter reducing the probability of subsequent LTP induction at these and potentially also at neighboring, nonpotentiated synapses.

To examine whether the failure to induce LTP was associated with altered spine calcium signaling, we monitored calcium transients using confocal microscopy. Purkinje cells were loaded with the fluorescent calcium indicator Oregon Green BAPTA-2 (200 $\mu \mathrm{M}$; excitation wavelength: $488 \mathrm{~nm}$ ) (Fig. 9B). Intrinsic plasticity was triggered by application of the current injection protocol, and was assessed as described above (spike count) (Fig. 9C). Dendritic calcium transients were elicited by $100 \mathrm{~Hz}$ PF stimulation (2-8 pulses) (Fig. 9D) at intervals of typically $2 \mathrm{~min}$ (in some experiments $0.5 \mathrm{~min}$ ). After application of the current injection protocol, spine calcium signaling was enhanced (Fig. 9E, F). The parameter of calcium transients that was most affected was the area under the curve, whereas the peak value was only moderately enhanced (area from 0 to $800 \mathrm{~ms}: 158.9 \pm 25.8 \% ; p=0.025$; peak: $113.6 \pm 6.6 \% ; p=0.02 ; t=0-12 \mathrm{~min}$ after tetanization; $n=7$ ) (Fig. $9 F, G$ ). In the absence of tetanization, calcium transients stayed stable (area: $93.4 \pm 12.2 \% ; p=0.30$; peak: $96.0 \pm$ $7.8 \% ; p=0.32 ; n=7$ ) (supplemental Fig. 10, available at www. jneurosci.org as supplemental material). There was a significant difference between changes in the area of spine calcium transients after tetanization and those recorded during the same time period under control conditions (Mann-Whitney $U$ test; area: $p=$ 0.04 ; peak: $p=0.16$ ). The increase in calcium transients was more pronounced in spines than associated shaft regions, in which an increase was observed as well, but did not reach statistical significance (area: $129.7 \pm 25.7 \% ; p=0.35 ; n=7$ ) (Fig. $9 H$ ). The change in spine calcium signaling was associated with an increase in intrinsic excitability $(167.6 \pm 5.4 \% ; p=0.002 ; t=0-12 \mathrm{~min}$ after tetanization; $n=7$ ) (Fig. 9C). A caveat of these experiments is that we can only provide a snapshot average of changes in calcium signaling and intrinsic excitability during a relatively short period (12 min) after tetanization. This limitation results from two technical factors: (1) data acquisition was adjusted to low frequencies to minimize light exposure (in most recordings images were taken all $2 \mathrm{~min}$ ), and the calcium transients require time averaging for analysis, and (2) after $12 \mathrm{~min}$ post-tetanization, changes in baseline fluorescence prevented monitoring of comparable calcium transients for longer periods of time. Within this limited time period, the changes in the spike rate and the 
spine calcium transients, respectively, did not show the same kinetics, with the increase in calcium signaling reaching saturation earlier (supplemental Fig. 11, available at www.jneurosci.org as supplemental material). This difference could be due to differences in the underlying cellular mechanisms, or simply differences in the location of these alterations within Purkinje cells. Together, these observations show that intrinsic plasticity is associated with an increase in spine calcium signaling that plateaus quickly after tetanization, and is most prominent for the area under the curve of calcium transients.

\section{Discussion}

Our study shows that the intrinsic excitability of Purkinje cells can be upregulated in an activity-dependent way both in vitro and in vivo. Intrinsic plasticity was observed when $\mathrm{PF}$ stimulation protocols were applied that induce PF-LTP. However, we could also trigger excitability increases using a current injection protocol that does not elicit LTP. The intrinsic plasticity amplitude varied significantly with the stimulation and recording conditions used. For example, the $1 \mathrm{~Hz}$ protocol was very efficient in vitro, but failed to trigger intrinsic plasticity in vivo. The $100 \mathrm{~Hz}$ protocol induced intrinsic plasticity in vivo, but the plasticity amplitude observed was relatively small. Two factors might have contributed to this observation: (1) intact inhibition reduces the plasticity amplitude, and (2) in our in vivo recordings the background spike rate was higher $(\sim 40 \mathrm{~Hz})$ than in the in vitro recordings ( $\sim 25-30 \mathrm{~Hz}$; intact inhibition), which might indicate that in the in vitro recordings the available plasticity range was higher to start with. Despite this amplitude variability, it should be stressed that intrinsic plasticity was observed both in vivo and in vitro, with inhibition blocked or intact, at different ages, in rats and in mice, and using different recording conditions, demonstrating that intrinsic plasticity is a robust and physiological phenomenon.

As intrinsic plasticity can be triggered by PF-LTP protocols, we examined whether signaling cascades involved in LTP are shared by intrinsic plasticity. In Purkinje cells, LTP is triggered by low calcium signals and the activation of $\mathrm{PP} 1,2 \mathrm{~A}$, and $2 \mathrm{~B}$, whereas LTD is evoked by high calcium signals and the activation of PKC and $\alpha$ CaMKII (Hansel et al., 2006; Jörntell and Hansel, 2006). Using phosphatase inhibitor drugs and L7-PP2B knockout mice, we observed that PP1,2A, and $2 \mathrm{~B}$ are not only involved in LTP induction, but also in intrinsic plasticity. In vestibular nucleus neurons, a similar form of intrinsic plasticity has been described, which results from a downregulation of CaMKII and a reduction of BK-type K channels (Nelson et al., 2005). We did not find a difference in intrinsic plasticity between $\alpha$ CaMKII knockout mice (Hansel et al., 2006) and wild-type littermates, suggesting that intrinsic plasticity is governed by a more complex interaction between phosphatases and kinases, such as PKA and $\mathrm{CK} 2$, rather than a simple molecular PP1/ $\alpha$ CaMKII switch. Accordingly, it is very possible that the various phosphatases and kinases involved have several molecular targets that complement each other in mediating intrinsic plasticity. For example, it has been shown in the hippocampus that PKA regulates the surface expression of SK2 channels (Ren et al., 2006), while CK2 reduces their calcium sensitivity (Allen et al., 2007). It remains to be determined what precise role protein phosphatases play in intrinsic plasticity and how they complement PKA and CK2 in regulating SK2 function.

Using the SK-type K channel antagonist apamin, we could show that a downregulation of SK channels partially mediates the enhancement of Purkinje cell excitability. These data are in line with the observation that intrinsic plasticity was associated with a reduction in the amplitude of the AHP (Fig. 1), which is partially mediated by apamin-sensitive SK conductances (Edgerton and Reinhart, 2003; Womack and Khodakhah, 2003). A caveat of our pharmacological approach is that by changing the membrane excitability, blockade of one type of channel might change the activation probability of other channels as well. It also needs to be pointed out that apamin application did not completely block intrinsic plasticity, suggesting that other conductances might additionally be altered. We therefore examined the involvement of other $\mathrm{K}$ conductances that have been implicated in excitability alterations. We were able to show that A-type K conductances and BK-type $\mathrm{K}$ conductances do not mediate this form of intrinsic plasticity. A remaining candidate is the $I_{\mathrm{h}}$ current, which can adjust Purkinje cell dendritic integration properties (Nolan et al., 2003; Angelo et al., 2007), but $I_{\mathrm{h}}$ has not been examined in this study.

What are the functional consequences of Purkinje cell intrinsic plasticity? In pyramidal cells, excitability increases and LTP complement each other: a downregulation of A-type K currents enhances the excitability of pyramidal cells and increases the LTP induction probability (Ramakers and Storm, 2002; Watanabe et al., 2002; Chen et al., 2006). LTP, in turn, is associated with enhanced local excitability that decreases the spike threshold (Daoudal et al., 2002; Cudmore and Turrigiano, 2004) and facilitates dendritic spike back-propagation (Frick et al., 2004). Recent studies show that SK channels play a key role in hippocampal LTP: not only does a downregulation of SK channels boost calcium signaling and promote LTP (Stackman et al., 2002; NgoAnh et al., 2005; Hammond et al., 2006), but LTP is associated with SK2 channel internalization, contributing to the overall EPSP increase (Lin et al., 2008). It seems that in pyramidal cells, changes in $\mathrm{K}$ conductances can locally act as positive regulators of synaptic gain.

A key difference between Purkinje cell intrinsic plasticity and hippocampal plasticity is the effect on subsequent LTP induction. While the enhanced excitability was associated with a small, nonsignificant increase in PF-EPSPs (Fig. 9A), Purkinje cell intrinsic plasticity lowers the probability for subsequent LTP induction, thus differentially affecting immediate synaptic responses and the ability to subsequently modify synaptic efficacy, respectively. A possible explanation for the reduced LTP induction probability is that intrinsic plasticity is accompanied by enhanced spine calcium signaling, as we demonstrated using confocal microscopy. In Purkinje cells, an amplification of calcium transients would promote LTD rather than LTP induction (Coesmans et al., 2004). Thus, the observed failure to induce LTP, or to obtain LTD instead, might result from two factors: (1) the calcium transients were too large for LTP, but too low for LTD induction, or (2) the LTD induction threshold was reached, but LTD was not induced, because of wash-out effects. The calcium signal parameter that was most dramatically altered was the area under the curve, whereas the peak was enhanced to a lower degree. It remains technically possible that changes in the calcium peak amplitude were underestimated because of dye saturation. Nevertheless, the confocal imaging data allow us to conclude that intrinsic plasticity is associated with a significant increase in calcium signaling recruited by $\mathrm{PF}$ activity.

Another key difference between consequences of intrinsic plasticity in Purkinje cells and pyramidal cells, respectively, is the observed alteration in the background spike rate. In contrast to pyramidal cells, which show low levels of spontaneous spike activity (Margrie et al., 2002), Purkinje cells are characterized by 
high spontaneous discharge rates of $30-80 \mathrm{~Hz}$ (Simpson et al., 1996). Increases in this spontaneous spike frequency lower the signal-to-noise ratio, and thus the PF readout (McKay et al., 2007). Here, we observed that Purkinje cell intrinsic plasticity is associated with a lasting increase in the spontaneous spike rate, which did not affect the tonic spike rate of DCN neurons, but lowered the net impact of PF signaling. Since pyramidal cells operate at far lower spontaneous spike frequencies, they cannot similarly control the impact of synaptic signaling by adjusting the background spike rate.

Purkinje cell intrinsic plasticity can be triggered by PF stimulation protocols that also elicit LTP. Strong PF activity will therefore induce LTP at the activated synapses, and the strengthened inputs, as much as neighboring nonpotentiated inputs, will be exposed to the enhanced excitability that accompanies LTP induction. Hippocampal recordings show that enhanced excitability can amplify EPSPs by removing the "brakes" imposed by SK channel activity (Lin et al., 2008). In our study, we also observed that intrinsic plasticity (current step protocol) slightly enhances EPSPs (Fig. 9A) and the spike output (Fig. $8 A, B$ ), but this trend did not reach significance. It seems that, if anything, the enhanced excitability might weakly amplify EPSPs, which would particularly benefit strong, potentiated PF synapses that are likely to reach the spike threshold. In contrast, the weaker, nonpotentiated synapses are more strongly affected by the Purkinje cellspecific intrinsic plasticity features that rather have a negative impact on synaptic gain: (1) intrinsic plasticity lowers the probability for subsequent LTP induction, thus lowering the chance for weaker synapses to be potentiated at a later time point, and (2) the enhanced spontaneous Purkinje cell spike rate lowers the signal-to-noise ratio and reduces the PF readout, which will affect weaker PF synapses more dramatically than stronger ones. The reduced probability for subsequent LTP induction also ensures that the overall excitatory drive stays within limits after a set of synapses was potentiated. In this scenario, intrinsic plasticity closely interacts with LTP to optimally adjust the impact of PF signaling. Available data on cerebellar learning collected in vivo do not allow us to draw conclusions on the relative contribution of synaptic and intrinsic plasticity mechanisms, but provide an outlook on the physiological relevance of a potentiation of synaptic/intrinsic response properties. When applied in vivo, the same $100 \mathrm{~Hz}$ PF burst protocol used here causes a dramatic increase in cutaneous PF receptive fields in Purkinje cells, which can be reversed by application of an LTD protocol (CF costimulation) (Jörntell and Ekerot, 2002). It is conceivable that this increase in receptive field size results from PF-LTP (the LTD protocol only triggers a reversal when applied to the same set of PF synapses), but that the strengthened synapses are further amplified by an associated increase in excitability (Jörntell and Hansel, 2006). Moreover, mice with a Purkinje cell-specific knock-out of PP2B show impaired LTP and intrinsic plasticity, but LTD is unaffected. Surprisingly, these mice have severe motor learning deficits, suggesting that both synaptic and intrinsic potentiation mechanisms contribute to cerebellar motor learning (our unpublished data). These observations are in line with previous notions that multiple plasticity mechanisms beyond LTD might be involved in cerebellar learning (Raymond and Lisberger, 1998; Hansel et al., 2001).

\section{References}

Aizenman CD, Linden DJ (2000) Rapid, synaptically driven increases in the intrinsic excitability of cerebellar deep nuclear neurons. Nat Neurosci 3:109-111.

Allen D, Fakler B, Maylie J, Adelman JP (2007) Organization and regulation of small conductance $\mathrm{Ca}^{2+}$-activated $\mathrm{K}^{+}$channel multiprotein complexes. J Neurosci 27:2369-2376.

Alviña K, Walter JT, Kohn A, Ellis-Davies G, Khodakhah K (2008) Questioning the role of rebound firing in the cerebellum. Nat Neurosci 11:1256-1258.

Angelo K, London M, Christensen SR, Häusser M (2007) Local and global effects of $I_{\mathrm{h}}$ distribution in dendrites of mammalian neurons. J Neurosci 27:8643-8653.

Armano S, Rossi P, Taglietti V, D’Angelo E (2000) Long-term potentiation of intrinsic excitability at the mossy fiber-granule cell synapse of rat cerebellum. J Neurosci 20:5208-5216.

Barski JJ, Dethleffsen K, Meyer M (2000) Cre recombinase expression in cerebellar Purkinje cells. Genesis 28:93-98.

Belmeguenai A, Hansel C (2005) A role for protein phosphatases 1, 2A, and 2B in cerebellar long-term potentiation. J Neurosci 25:10768-10772.

Bengtsson F, Jörntell H (2007) Ketamine and xylazine depress sensoryevoked parallel fiber and climbing fiber responses. J Neurophysiol 98:1697-1705.

Bildl W, Strassmaier T, Thurm H, Andersen J, Eble S, Oliver D, Knipper M, Mann M, Schulte U, Adelman JP, Fakler B (2004) Protein kinase CK2 is coassembled with small conductance $\mathrm{Ca}^{2+}$-activated $\mathrm{K}^{+}$channels and regulates channel gating. Neuron 43:847-858.

Brager DH, Johnston D (2007) Plasticity of intrinsic excitability during long-term depression is mediated through mGluR-dependent changes in $I_{\mathrm{h}}$ in hippocampal CA1 pyramidal neurons. J Neurosci 27:13926-13937.

Chadderton P, Margrie TW, Häusser M (2004) Integration of quanta in cerebellar granule cells during sensory processing. Nature 428:856-860.

Chen X, Yuan LL, Zhao C, Birnbaum SG, Frick A, Jung WE, Schwarz TL, Sweatt JD, Johnston D (2006) Deletion of Kv4.2 gene eliminates dendritic A-type K current and enhances induction of long-term potentiation in hippocampal CA1 pyramidal neurons. J Neurosci 26:12143-12151.

Cingolani LA, Gymnopoulos M, Boccaccio A, Stocker M, Pedarzani P (2002) Developmental regulation of small conductance $\mathrm{Ca}^{2+}$-activated $\mathrm{K}^{+}$ channel expression and function in rat Purkinje neurons. J Neurosci 22:4456-4467.

Coesmans M, Weber JT, De Zeeuw CI, Hansel C (2004) Bidirectional parallel fiber plasticity in the cerebellum under climbing fiber control. Neuron 44:691-700.

Cudmore RH, Turrigiano GG (2004) Long-term potentiation of intrinsic excitability in LV visual cortical neurons. J Neurophysiol 92:341-348.

Daoudal G, Hanada Y, Debanne D (2002) Bidirectional plasticity of excitatory postsynaptic potential (EPSP)-spike coupling in CA1 hippocampal pyramidal neurons. Proc Natl Acad Sci U S A 99:14512-14517.

Dean P, Porrill J, Ekerot CF, Jörntell H (2010) The cerebellar microcircuit as an adaptive filter: experimental and computational evidence. Nat Rev Neurosci 11:30-43.

Edgerton JR, Reinhart PH (2003) Distinct contributions of small and large conductance $\mathrm{Ca} 2+$-activated $\mathrm{K}+$ channels to rat Purkinje neuron function. J Physiol 548:53-69.

Elgersma Y, Fedorov NB, Ikonen S, Choi ES, Elgersma M, Carvalho OM, Giese KP, Silva AJ (2002) Inhibitory autophosphorylation of CaMKII controls PSD association, plasticity, and learning. Neuron 36:493-505.

Fan Y, Fricker D, Brager DH, Chen X, Lu HC, Chitwood RA, Johnston D (2005) Activity-dependent decrease of excitability in rat hippocampal neurons through increases in Ih. Nat Neurosci 8:1542-1551.

Frick A, Johnston D (2005) Plasticity of dendritic excitability. J Neurobiol 64:100-115.

Frick A, Magee J, Johnston D (2004) LTP is accompanied by an enhanced local excitability of pyramidal neuron dendrites. Nat Neurosci 7:126-135.

Gauck V, Jaeger D (2000) The control of rate and timing of spikes in the deep cerebellar nuclei by inhibition. J Neurosci 20:3006-3016.

Hammond RS, Bond CT, Strassmaier T, Ngo-Anh TJ, Adelman JP, Maylie J, Stackman RW (2006) Small-conductance $\mathrm{Ca}^{2+}$-activated $\mathrm{K}^{+}$channel type 2 (SK2) modulates hippocampal learning, memory, and synaptic plasticity. J Neurosci 26:1844-1853.

Hansel C, Linden DJ, D’Angelo E (2001) Beyond parallel fiber LTD: the diversity of synaptic and non-synaptic plasticity in the cerebellum. Nat Neurosci 4:467-475.

Hansel C, de Jeu M, Belmeguenai A, Houtman SH, Buitendijk GH, Andreev D, De Zeeuw CI, Elgersma Y (2006) $\alpha$ CaMKII is essential for cerebellar LTD and motor learning. Neuron 51:835-843.

Häusser M, Clark BA (1997) Tonic synaptic inhibition modulates neuronal 
output pattern and spatiotemporal synaptic integration. Neuron 19:665-678.

Ito M (1984) The cerebellum and neural control. New York: Raven.

Jahnsen H (1986) Electrophysiological characteristics of neurones in the guinea-pig deep cerebellar nuclei in vitro. J Physiol 372:129-147.

Jörntell H, Ekerot CF (2002) Reciprocal bidirectional plasticity of parallel fiber receptive fields in cerebellar Purkinje cells and their afferent interneurons. Neuron 34:797-806.

Jörntell H, Ekerot CF (2006) Properties of somatosensory synaptic integration in cerebellar granule cells in vivo. J Neurosci 26:11786-11797.

Jörntell H, Hansel C (2006) Synaptic memories upside down: bidirectional plasticity at cerebellar parallel fiber-Purkinje cell synapses. Neuron 52:227-238.

LeDoux MS, Hurst DC, Lorden JF (1998) Single-unit activity of cerebellar nuclear cells in the awake genetically dystonic rat. Neuroscience 86:533-545.

Lev-Ram V, Wong ST, Storm DR, Tsien RY (2002) A new form of cerebellar long-term potentiation is postsynaptic and depends on nitric oxide but not cAMP. Proc Natl Acad Sci U S A 99:8389-8393.

Lin MT, Luján R, Watanabe M, Adelman JP, Maylie J (2008) SK2 channel plasticity contributes to LTP at Schaffer collateral-CA1 synapses. Nat Neurosci 11:170-177.

Margrie TW, Brecht M, Sakmann B (2002) In vivo, low resistance, wholecell recordings from neurons in the anaesthetized and awake mammalian brain. Pflugers Arch 444:491-498.

McKay BE, Engbers JDT, Mehaffey WH, Gordon GRJ, Molineux ML, Bains JS, Turner RW (2007) Climbing fiber discharge regulates cerebellar functions by controlling the intrinsic characteristics of Purkinje cell output. J Neurophysiol 97:2590-2604.

Mittmann W, Häusser M (2007) Linking synaptic plasticity and spike output at excitatory and inhibitory synapses onto cerebellar Purkinje cells. J Neurosci 27:5559-5570.

Moyer JR Jr, Thompson LT, Disterhoft JF (1996) Trace eyeblink conditioning increases CA1 excitability in a transient and learning-specific manner. J Neurosci 16:5536-5546.

Mozzachiodi R, Byrne JH (2010) More than synaptic plasticity: role of nonsynaptic plasticity in learning and memory. Trends Neurosci 33:17-26.

Nelson AB, Gittis AH, du Lac S (2005) Decreases in CaMKII activity trigger persistent potentiation of intrinsic excitability in spontaneously firing vestibular nucleus neurons. Neuron 46:623-631.

Ngo-Anh TJ, Bloodgood BL, Lin M, Sabatini BL, Maylie J, Adelman JP (2005) SK channels and NMDA receptors form a Ca2+-mediated feedback loop in dendritic spines. Nat Neurosci 8:642-649.

Nolan MF, Malleret G, Lee KH, Gibbs E, Dudman JT, Santoro B, Yin D, Thompson RF, Siegelbaum SA, Kandel ER, Morozov A (2003) The hyperpolarization-activated $\mathrm{HCN} 1$ channel is important for motor learning and neuronal integration by cerebellar Purkinje cells. Cell 115: 551-564.

Oh MM, McKay BM, Power JM, Disterhoft JF (2009) Learning-related postburst afterhyperpolarization reduction in CA1 pyramidal neurons is mediated by protein kinase A. Proc Natl Acad Sci U S A 106:1620-1625.

Pedroarena CM, Schwarz C (2003) Efficacy and short-term plasticity at GABAergic synapses between Purkinje and cerebellar nuclei neurons. J Neurophysiol 89:704-715.

Piochon C, Irinopoulou T, Brusciano D, Bailly Y, Mariani J, Levenes C (2007) NMDA receptor contribution to the climbing fiber response in the adult mouse Purkinje cell. J Neurosci 27:10797-10809.

Ramakers GM, Storm JF (2002) A postsynaptic transient K current modulated by arachidonic acid regulates synaptic integration and threshold for LTP induction in hippocampal pyramidal cells. Proc Natl Acad Sci U S A 99:10144-10149.

Rancz EA, Häusser M (2006) Dendritic calcium spikes are tunable triggers of cannabinoid release and short-term synaptic plasticity in cerebellar Purkinje neurons. J Neurosci 26:5428-5437.
Raymond JL, Lisberger SG (1998) Neural learning rules for the vestibuloocular reflex. J Neurosci 18:9112-9129.

Ren Y, Barnwell LF, Alexander JC, Lubin FD, Adelman JP, Pfaffinger PJ, Schrader LA, Anderson AE (2006) Regulation of surface localization of the small conductance $\mathrm{Ca}^{2+}$-activated potassium channel, SK2, through direct phosphorylation by cAMP-dependent protein kinase. J Biol Chem 281:11769-11779.

Rosenkranz JA, Frick A, Johnston D (2009) Kinase-dependent modification of dendritic excitability after long-term potentiation. J Physiol 587: $115-125$.

Sailer CA, Kaufmann WA, Marksteiner J, Knaus HG (2004) Comparative immunohistochemical distribution of three small-conductance Ca2+activated potassium channel subunits, SK1, SK2, and SK3 in mouse brain. Mol Cell Neurosci 26:458-469.

Sausbier M, Hu H, Arntz C, Feil S, Kamm S, Adelsberger H, Sausbier U, Sailer CA, Feil R, Hofmann F, Korth M, Shipston MJ, Knaus HG, Wolfer DP, Pedroarena CM, Storm JF, Ruth P (2004) Cerebellar ataxia and Purkinje cell dysfunction caused by $\mathrm{Ca} 2+$-activated $\mathrm{K}+$ channel deficiency. Proc Natl Acad Sci U S A 101:9474-9478.

Schreurs BG, Gusev PA, Tomsic D, Alkon DL, Shi T (1998) Intracellular correlates of acquisition and long-term memory of classical conditioning in Purkinje cell dendrites in slices of rabbit cerebellar lobule HVI. J Neurosci 18:5498-5507.

Seutin V, Johnson SW (1999) Recent advances in the pharmacology of quaternary salts of bicuculline. Trends Pharm Sci 20:268-270.

Simpson JI, Wylie DR, De Zeeuw CI (1996) On climbing fiber signals and their consequence(s). Behav Brain Sci 19:384-398.

Smith SL, Otis TS (2005) Pattern-dependent, simultaneous plasticity differentially transforms the input-output relationship of a feedforward circuit. Proc Natl Acad Sci U S A 102:14901-14906.

Sourdet V, Russier M, Daoudal G, Ankri N, Debanne D (2003) Long-term enhancement of neuronal excitability and temporal fidelity mediated by metabotropic glutamate receptor subtype 5. J Neurosci 23:10238-10248.

Stackman RW, Hammond RS, Linardatos E, Gerlach A, Maylie J, Adelman JP, Tzounopoulos $\mathrm{T}$ (2002) Small conductance $\mathrm{Ca}^{2+}$-activated $\mathrm{K}^{+}$channels modulate synaptic plasticity and memory encoding. J Neurosci 22:10163-10171.

Telgkamp P, Raman IM (2002) Depression of inhibitory synaptic transmission between Purkinje cells and neurons of the cerebellar nuclei. J Neurosci 22:8447-8457.

Walter JT, Khodakhah K (2006) The linear computational algorithm of cerebellar Purkinje cells. J Neurosci 26:12861-12872.

Walter JT, Alviña K, Womack MD, Chevez C, Khodakhah K (2006) Decreases in the precision of Purkinje cell pacemaking cause cerebellar dysfunction and ataxia. Nat Neurosci 9:389-397.

Wang Z, Xu NL, Wu CP, Duan S, Poo MM (2003) Bidirectional changes in spatial dendritic integration accompanying long-term synaptic modifications. Neuron 37:463-472.

Watanabe S, Hoffman DA, Migliore M, Johnston D (2002) Dendritic K+ channels contribute to spike-timing dependent long-term potentiation in hippocampal pyramidal neurons. Proc Natl Acad Sci U S A 99:83668371.

Womack MD, Khodakhah K (2003) Somatic and dendritic smallconductance calcium-activated potassium channels regulate the output of cerebellar Purkinje neurons. J Neurosci 23:2600-2607.

Zeng H, Chattarji S, Barbarosie M, Rondi-Reig L, Philpot BD, Miyakawa T, Bear MF, Tonegawa S (2001) Forebrain-specific calcineurin knockout selectively impairs bidirectional synaptic plasticity and working/episodiclike memory. Cell 107:617-629.

Zhang W, Linden DJ (2003) The other side of the engram: experiencedriven changes in neuronal intrinsic excitability. Nat Rev Neurosci 4:885900 . 